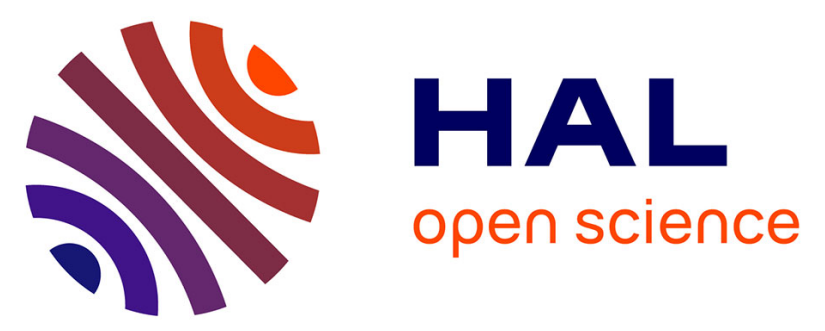

\title{
Determination of cirrus radiative parameters from combination between active and passive remote sensing measurements during FRENCH/DIRAC 2001
}

Gérard Brogniez, Frédéric Parol, Laurianne Bécu, Jacques Pelon, Olivier Jourdan, Jean-François Gayet, Frédérique Auriol, Christian Verwaerde, Jean-Yves Balois, Bahaiddin Damiri

\section{To cite this version:}

Gérard Brogniez, Frédéric Parol, Laurianne Bécu, Jacques Pelon, Olivier Jourdan, et al.. Determination of cirrus radiative parameters from combination between active and passive remote sensing measurements during FRENCH/DIRAC 2001. Atmospheric Research, 2004, 72 (1-4), pp.425-452. 10.1016/j.atmosres.2004.03.026 . hal-01982549

\section{HAL Id: hal-01982549 \\ https://hal.science/hal-01982549}

Submitted on 3 Dec 2021

HAL is a multi-disciplinary open access archive for the deposit and dissemination of scientific research documents, whether they are published or not. The documents may come from teaching and research institutions in France or abroad, or from public or private research centers.
L'archive ouverte pluridisciplinaire HAL, est destinée au dépôt et à la diffusion de documents scientifiques de niveau recherche, publiés ou non, émanant des établissements d'enseignement et de recherche français ou étrangers, des laboratoires publics ou privés. 


\title{
Determination of cirrus radiative parameters from combination between active and passive remote sensing measurements during FRENCH/DIRAC 2001
}

\author{
Gérard Brogniez ${ }^{\mathrm{a}, *}$, Frédéric Parol ${ }^{\mathrm{a}}$, Laurianne Bécu ${ }^{\mathrm{a}}$, \\ Jacques Pelon ${ }^{b}$, Olivier Jourdan ${ }^{c}$, Jean-François Gayet ${ }^{c}$, \\ Frédérique Auriol $^{\mathrm{a}}$, Christian Verwaerde ${ }^{\mathrm{a}}$, \\ Jean-Yves Balois ${ }^{\mathrm{a}}$, Bahaiddin Damiri ${ }^{\mathrm{d}}$ \\ a Laboratoire d'Optique Atmosphérique, Université des Sciences et Technologies de Lille, \\ Villeneuve d'Ascq, France \\ ${ }^{\mathrm{b}}$ Service d'Aéronomie du CNRS, Université Pierre et Marie Curie, Paris, France \\ ${ }^{\mathrm{c}}$ Laboratoire de Météorologie Physique, Université Blaise Pascal, Clermont-Ferrand, France \\ ${ }^{\mathrm{d}}$ Cimel Electronique, Paris, France
}

Received 30 July 2003; received in revised form 16 January 2004; accepted 31 March 2004

\begin{abstract}
In the context of the next AQUA Train satellite experiment, airborne measurements were carried out to simulate satellite measurements. They were conducted between September 25 and October 12, 2001, off the coast of southern France over the Atlantic Ocean and over the Mediterranean Sea, respectively. During the intensive Field Radiation Experiment on Natural Cirrus and High-level clouds (FRENCH/DIRAC 2001), natural ice clouds were sampled from in situ and remote sensing measurements. On October 5 and 7, 2001, cirrus cloud decks were described by a complete data set acquired by: (i) in situ microphysical instruments onboard the TBM-700 aircraft: PMS probe, and Polar Nephelometer (ii) and downward-looking radiative instruments onboard the Mystère 20 aircraft: an infrared radiometer, a lidar, a visible imager with polarisation capabilities, and a middle infrared radiometer. Moreover, classical thermodynamical measurements were carried out onboard the Mystère 20. Mean microphysical characteristics of cirrus deck are derived from interpretation of remote sensing measurements. These properties are
\end{abstract}

* Corresponding author. Tel.: +33-3-20-43-66-43; fax: +33-3-20-43-43-42.

E-mail address: gerard.brogniez@univ-lille1.fr (G. Brogniez). 
compared with those derived from in situ microphysical measurements in order to evaluate the radiative impact of natural cirrus clouds.

(C) 2004 Elsevier B.V. All rights reserved.

Keywords: Cirrus clouds; Multi-sensor observations; Optical properties; Radiative properties

\section{Introduction}

Cirrus and high-level clouds permanently cover nearly $20 \%$ of the globe (Warren et al., 1988), and their impact on climate has been well established (Liou, 1986). One of the objectives of the World Climate Programme (WCP, 1986) is to improve our knowledge of cirrus clouds, in order to perform reliable prediction of their impact on the Earth radiation budget. This goal requires an appropriate description - in completeness, representatives and accuracy — of their physical and optical properties to be used in models. It has been shown that the shape and size distribution of crystals modify to a large extent the scattering properties of cirrus clouds (e.g. Takano and Liou, 1989; Brogniez et al., 1992; C.-Labonnote et al., 2000; 2001; Knapp et al., 1999), and consequently their radiative properties.

Cirrus clouds must be well documented in order to derive their microphysical and optical properties, which are requested to perform process studies, parameterization and validation activities for atmospheric model applications. Until now, few field airborne experiments combining in situ and radiative measurements have been conducted on natural cirrus. In fact, the study of cirrus clouds is not easy because of their high altitude, but it is necessary because of the large variability of this type of clouds: large spatial inhomogeneity, and highly variable microphysical properties (Miloshevich and Heymsfield, 1996). Several field airborne experiments were conducted in USA and Europe: the two First International Satellite and Cloud Climatology Project Regional experiments FIRE I and FIRE II in 1986 and 1991, respectively (special issues of Monthly Weather Review, Vol. 118, no. 11, 1990 and Journal of Atmospheric Sciences, Vol. 52, no. 23, 1995), the International Cirrus Experiment (ICE'89) in 1989 (Raschke et al., 1990), and European Cloud Radiative Experiment (EUCREX'93 and EUCREX'94) (Raschke et al., 1998; Sauvage et al., 1999; Chepfer et al., 1999). During the field campaigns, in situ probes, passive and active remote sensors, either airborne or ground-based, were deployed to document different cirrus cloud layers at the mesoscale while satellite data provided synoptic scale observations.

It is well known that a synergism of remote sensors is a key issue for the retrieval of cirrus cloud characteristics that are relevant to radiative transfer and parameterization studies. This synergism will be achieved with the AQUA-Train spaceborne mission, which consists of four main platforms that fly in formation with each other: EOS-Aqua (which carries MODIS and CERES radiometers), PARASOL (which carries POLDER), CALIPSO (which carries a lidar and the thermal infrared imager IIR), and CLOUDSAT (which carries a cloud profiling radar). The complete A-Train will be in space at the beginning of 2005.

In this paper, we illustrate the potential interest in combining a great deal of this kind of remote sensors, the visible imager POLDER (POLarisation and Directionality of the 
Earth's Reflectances), the middle infrared polarized radiometer MINIMIR (mini Middle Infrared Radiometer), the three thermal infrared band radiometer CLIMAT-AV (Conveyable Low-noise Infrared radiometer for Measurements of Atmosphere and ground surface Targets-Airborne Version, manufactured by CIMEL, Paris, France), and the backscatter lidar LEANDRE (Lidar embarqué pour l'Étude des Aérosols, Nuages, Dynamique, Rayonnement et Espèces minoritaires). During FRENCH/DIRAC 2001 (Field Radiation Experiment on Natural Cirrus and High-level clouds), a field campaign which was held in Golfe de Gascogne, and Golfe du Lion, France, between September 25 and October 12, 2001, these abovementioned remote sensors instruments were installed onboard the Mystère 20 aircraft. In situ sensors were installed onboard the aircraft TBM-700: OAP2D2-C (Optical Array Probe-Cloud, manufactured by Particle Measuring System, USA), and Polar Nephelometer (manufactured by Laboratoire de Météorologie Physique, Clermont-Ferrand, France). When possible, these two aircrafts were operated simultaneously, Mystère 20 above the cirrus cloud, while TBM-700 inside it. The FRENCH/ DIRAC 2001 experiment was implemented in the context of the near future spatial experiment Aqua Train, which will join active and passive remote sensing instruments. So it is of great interest for scientific teams involved in this spatial experiment, who need feasibility study and validation experiments. The instruments carried by the two aircrafts constituted an original set which will allow for studying the synergism between the different types of sensor in order to prepare future satellite experiments. The first goal of this present paper is to describe the data set acquired during the FRENCH/DIRAC 2001 campaign. Preliminary retrievals of microphysical cloud properties are also presented and some of the findings using the remote sensors are validated by in situ measurements.

In this paper, we report on two well-documented cirrus cloud cases (October 5 and 7, 2001) over the Atlantic Ocean off the Golfe de Gascogne. Section 2 presents an overview of FRENCH/DIRAC 2001 and the synoptic conditions prevailing on October 5 and 72001 (Missions 06 and 08, respectively). Section 3 presents the remote sensing instruments and deals with the determination of the thermodynamic phase of water in the cloud during Mission 06. Section 4 illustrates the retrieval of ice cloud microphysical properties during Mission 08, using in situ and remote sensing measurements. Section 5 gives preliminary conclusions concerning the retrieval of the cirrus cloud microphysical properties using the combination between all the airborne instruments during FRENCH/DIRAC 2001.

\section{Overview of FRENCH/DIRAC 2001}

FRENCH/DIRAC is a French programme focused on radiative properties of cirrus and their link with microphysical properties. It has been promoted by DGA (Direction Générale des Armées) and CNRS/INSU (Centre National de la Recherche Scientifique/ Institut National des Sciences de l'Univers) in 2001.

Two aircrafts were operated during FRENCH/DIRAC 2001: (i) a turboprop TBM-700 operated by EADS-SOCATA (European Aeronautic Defence and Space-SOciété de Construction d'Avions de Tourisme et d'Affaire), (ii) and a jet Mystère 20 (M-20) operated by IGN/INSU (Institut Géographique National/Institut National des Sciences de l'Univers). Table 1 presents the aircraft performance and instrumental payloads. 
Table 1

Aircraft performance and instrumental payloads

\begin{tabular}{|c|c|c|}
\hline & TBM 700 (in situ probes) & Mystère 20 (remote sensing instruments) \\
\hline Ceiling altitude & $10500 \mathrm{~m}$ & $12000 \mathrm{~m}$ \\
\hline Cruising airspeed & $140 \mathrm{~m} \mathrm{~s}^{-1}$ & $190 \mathrm{~m} \mathrm{~s}^{-1}$ \\
\hline Endurance & $4 \mathrm{~h}$ & $2 \mathrm{~h}, 30-3 \mathrm{~h}$ \\
\hline \multirow[t]{7}{*}{ Instrumentation } & Polar Nephelometer OAPX-2D-C & Lidar LEANDRE (530 and $1060 \mathrm{~nm}$ ) \\
\hline & & Polarimeter POLDER (443 to $910 \mathrm{~nm}$ ) \\
\hline & & Infrared radiometer CLIMAT \\
\hline & & $(8.7,10.8$ and $12 \mu \mathrm{m})$ \\
\hline & & Middle Infrared polarimeter MINIMIR \\
\hline & & $(670$ to $2200 \mathrm{~nm})$ \\
\hline & & In situ probes $(p, T, u)$ \\
\hline
\end{tabular}

Spectral domains of the remote sensing instruments are also indicated.

The two aircrafts were based at the Tarbes-Ossun airfield $\left(43^{\circ} 20^{\prime} \mathrm{N}, 0^{\circ} 01^{\prime} \mathrm{E}\right)$. A summary of missions undertaken during FRENCH/DIRAC, with date, location, and meteorological conditions, is presented in Table 2.

When coordinated flights were possible, M-20 overflew the cirrus layer at a constant altitude, whereas TBM-700 flew inside the cirrus layer (Fig. 1).

In the following sections, we report on the retrieval of cloud characteristics during Missions 06 and 08 on October 5 and 7, 2001, respectively.

The flight tracks for Missions 06 and 08 are displayed in Fig. 2. The Golfe de Gascogne was overflown during these missions. The parts of M-20 flight in bold line indicate studied specific parts of the cloud. The arrows stand for the flight heading.

Fig. 3 illustrates the atmospheric conditions at 1200 UTC on October 7, 2001 in the southwest part of France. As displayed on this figure, temperature and humidity profiles from the radiosoundings of Bordeaux, France $\left(44.50^{\circ} \mathrm{N}, 0.34^{\circ} \mathrm{W}\right)$ and Santander, Spain $\left(43.28^{\circ} \mathrm{N}, 3.48^{\circ} \mathrm{W}\right)$ were in good agreement. It was also the case on October 5,2001 . That is the reason why mean profiles were used to characterize the atmosphere in the flight area. On October 7, the tropopause height was at $10.5 \mathrm{~km}$ (with an uncertainty of $0.3 \mathrm{~km}$ ), the temperature was $-62{ }^{\circ} \mathrm{C}$, and the mean lapse rate in the upper troposphere was $-6.9{ }^{\circ} \mathrm{C} /$ $\mathrm{km}$. Up to $30 \mathrm{~km}$, the atmospheric profiles were extrapolated using mid-latitude climatic profile (Mc Clatchey et al., 1971).

\section{Description of remote sensing instruments and first qualitative interpretations of radiation measurements: Mission 06 case study (October 5, 2001)}

In this section, we present the remote sensors, and the methodologies used to derive the thermodynamic phase of clouds.

\subsection{LEANDRE}

The lidar LEANDRE (Pelon et al., 1990) was installed on board the M-20 and was operated in nadir view configuration. The transmitter is composed of a Nd-YAG laser 
Table 2

Summary of the various missions conducted during FRENCH/DIRAC 2001

\begin{tabular}{|c|c|c|c|c|c|}
\hline $\begin{array}{l}\text { FRENCH } \\
\text { Mission }\end{array}$ & Date & TBM & M20 & $\begin{array}{l}\text { Meteorological } \\
\text { conditions }\end{array}$ & Comments \\
\hline Transit 00 & $09 / 20$ & - & $\mathrm{X}$ & $\begin{array}{l}\text { Low and mean } \\
\text { level clouds }\end{array}$ & \\
\hline 01 & $09 / 25$ & $\mathrm{X}$ & $\mathrm{X}$ & $\begin{array}{l}\text { Cirrus over sea } \\
(6-10 \mathrm{~km}) \text { with } \\
\text { few cumulus }\end{array}$ & $\begin{array}{l}\text { Pressure problem and } \\
\text { no GPS on board TBM } \\
\text { No TBM measurements } \\
\text { over sea } \\
\text { Less cumulus at the } \\
\text { end of leg over sea }\end{array}$ \\
\hline 02 & $09 / 28$ & $\mathrm{X}$ & $\mathrm{X}$ & $\begin{array}{l}\text { Cirrus }(6-12 \mathrm{~km}) \\
\text { and altostratus }\end{array}$ & $\begin{array}{l}\text { M20 at the cirrus top } \\
\text { No GPS on board TBM }\end{array}$ \\
\hline 03 & $09 / 30$ & - & $\mathrm{X}$ & $\begin{array}{l}\text { Cirrus }(6-12 \mathrm{~km}) \\
\text { and altostratus }(3 \mathrm{~km})\end{array}$ & M20 above cirrus \\
\hline 04 & $10 / 01$ & - & $\mathrm{X}$ & $\begin{array}{l}\text { Cirrus }(9-11 \mathrm{~km}) \\
\text { and Stratocumulus }(1 \mathrm{~km})\end{array}$ & $\begin{array}{l}\text { Aerosol flight } \\
\text { Only cirrus clouds partly } \\
\text { covered under the aircraft }\end{array}$ \\
\hline 05 & $10 / 03$ & $\mathrm{X}$ & - & Cirrus & $\begin{array}{l}\text { TBM Test flight over land } \\
\text { (Toulouse area) }\end{array}$ \\
\hline 06 & $10 / 05 \mathrm{am}$ & $\mathrm{X}$ & $\mathrm{X}$ & $\begin{array}{l}\text { Cirrus over land } \\
\text { and altostratus. } \\
\text { Altostratus then dense } \\
\text { cirrus over sea }\end{array}$ & $\begin{array}{l}\text { Cirrus over land: TBM and M20 } \\
\text { Cirrus over sea: no TBM }\end{array}$ \\
\hline 07 & $10 / 05 \mathrm{pm}$ & $\mathrm{X}$ & $\mathrm{X}$ & $\begin{array}{l}\text { Cirrus over land and altostratus } \\
(4-12 \mathrm{~km}) \text {. Cirrus and } \\
\text { altostratus over sea }(4-12 \mathrm{~km})\end{array}$ & $\begin{array}{l}\text { Cirrus over land: TBM and M20 } \\
\text { Cirrus over sea: TBM and M20 }\end{array}$ \\
\hline 08 & $10 / 07$ & $\mathrm{X}$ & $\mathrm{X}$ & $\begin{array}{l}\text { Cirrus }(8-10 \mathrm{~km}) \text { and } \\
\text { dense altostratus }(4 \mathrm{~km})\end{array}$ & $\begin{array}{l}\text { Good simultaneous measurements } \\
\text { between TBM and M20 }\end{array}$ \\
\hline \multicolumn{6}{|c|}{ DIRAC Mission } \\
\hline 09 & $10 / 24$ & - & $\mathrm{X}$ & $\begin{array}{l}\text { Some cirrus, multilayered } \\
\text { clouds. Land and sea }\end{array}$ & Test flight \\
\hline 10 & $10 / 26$ & $\mathrm{X}$ & $\mathrm{X}$ & $\begin{array}{l}\text { Cirrus }(9-12 \mathrm{~km}) \text {, altostratus, } \\
\text { and cumulus. Land and sea }\end{array}$ & $\begin{array}{l}\text { Simultaneous flight between TBM } \\
\text { and M20 over sea (M20 above cirrus) }\end{array}$ \\
\hline 11 & $10 / 27$ & $\mathrm{X}$ & $\mathrm{X}$ & $\begin{array}{l}\text { Cirrus and altostratus }(4-12 \mathrm{~km}) \text {. } \\
\text { Land and sea }\end{array}$ & $\begin{array}{l}\text { Simultaneous flight between TBM } \\
\text { and M } 20 \text { over sea (M20 above cirrus) }\end{array}$ \\
\hline
\end{tabular}

First priority cases: October 5 and 7, and October 26 and 27. Second priority cases: September 25 and 30.

emitting a power of $60 \mathrm{~mJ}$ per pulse at the wavelength of $0.53 \mu \mathrm{m}$ and $100 \mathrm{~mJ}$ per pulse at $1.06 \mu \mathrm{m}$. The pulse repetition frequency is $10 \mathrm{~Hz}$. The two laser emissions are linearly polarized. The laser beam divergence of $2.5 \mathrm{mrad}$ gives a footprint of $2.5 \mathrm{~m}$ at $1 \mathrm{~km}$. The backscattered signal is collected by a receiver telescope $(30-\mathrm{cm}$ diameter, 3.5-mrad field-of-view). Three detection channels are recorded simultaneously: two polarized signals at $0.53 \mu \mathrm{m}\left(S_{/ /}\right.$and $S_{\perp}$ parallel and perpendicular to the incident polarisation, respectively, and one total signal at $1.06 \mu \mathrm{m}$. The vertical resolution along the line-of-sight is $15 \mathrm{~m}$; it is set by the transient digitizer sampling frequency (10 $\mathrm{MHz}$ ). Twelve lidar shots along a row are averaged to increase the signal-to-noise ratio. 


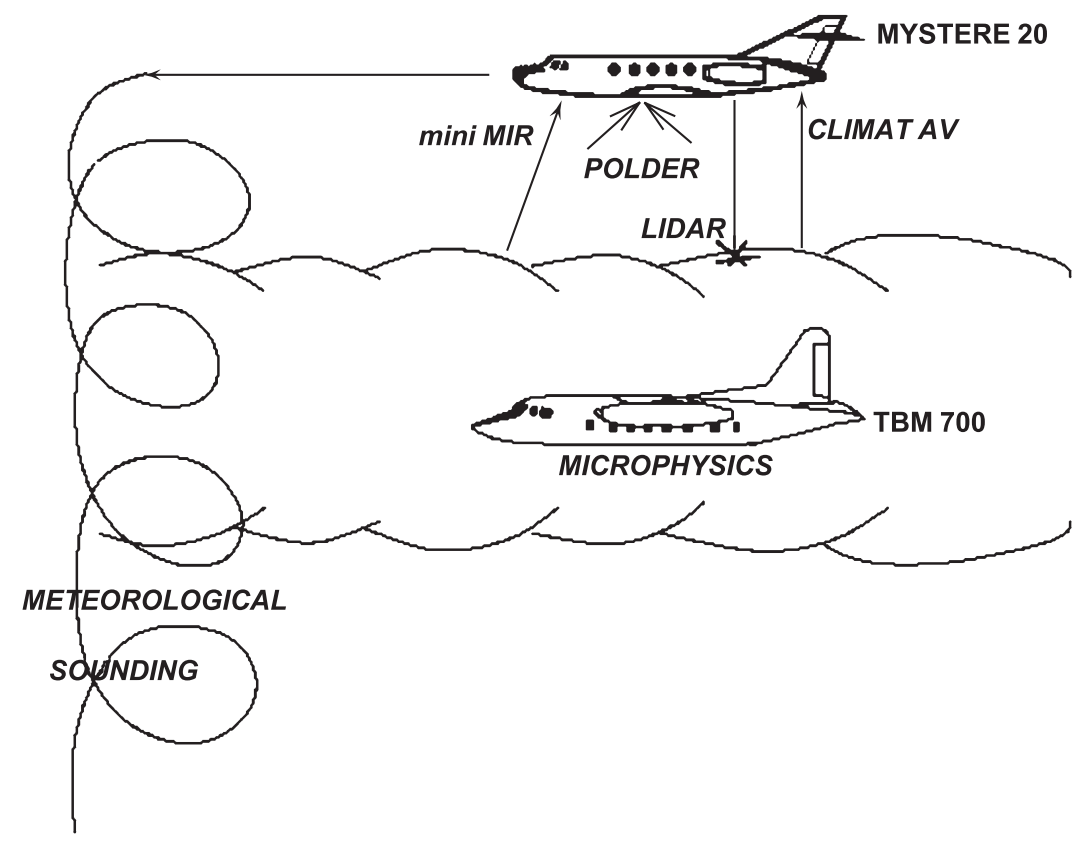

Fig. 1. Synoptic scheme of flight missions.

The lidar signal $S(p, z)$ after digitization can be written as:

$$
S(p, z)=\frac{C}{\left(z-z_{\mathrm{o}}\right)} \beta(p, z) \exp \left(-2 \eta \int_{z_{\mathrm{o}}}^{z} \alpha\left(p, z^{\prime}\right) \mathrm{d} z^{\prime}\right)
$$

where $p$ is the horizontal position (latitude, longitude) of the aircraft (i.e. of measurements), $z$ is the altitude, and $z_{\mathrm{o}}$ is the aircraft flight altitude, $\eta$ is a multiple scattering coefficient (Platt, 1979). $\beta(p, z)$ and $\alpha(p, z)$ are the total backscattering coefficient $\left(\mathrm{km}^{-1}\right.$ $\left.\mathrm{sr}^{-1}\right)$ and extinction coefficient $\left(\mathrm{km}^{-1}\right)$ for cloud particles and molecules, respectively. It is convenient to use the relationship $\beta(p, z)=k \alpha(p, z)$ linking $\alpha$ and $\beta$ where the backscatter to extinction ratio $k$ is defined by $k=(P(\pi) / 4 \pi)(P(\pi))$ is the normalised phase function in backscattering). The instrumental constant $C$ depends on the system characteristics, i.e. transmitted laser energy, receiver collecting area, optical efficiency, photo detector quantum yield, and electronic gain. Detailed explanations concerning the analysis of lidar signal are given, for example in Sauvage et al. (1999). The cloud layers are assigned by lidar, using a threshold algorithm (Young, 1995), with an estimated uncertainty of the order of 15 to $30 \mathrm{~m}$.

The backscatter lidar LEANDRE provides direct information on cirrus cloud structure (height, geometrical thickness), optical properties (profiles of extinction and backscatter coefficients) and parameters linked to the microphysical characteristics of cloud particles (backscatter-to-extinction lidar ratio, depolarisation ratio). For FRENCH 2001, the cirrus optical properties are derived only from the two $0.53-\mu \mathrm{m}$ polarized channels. 

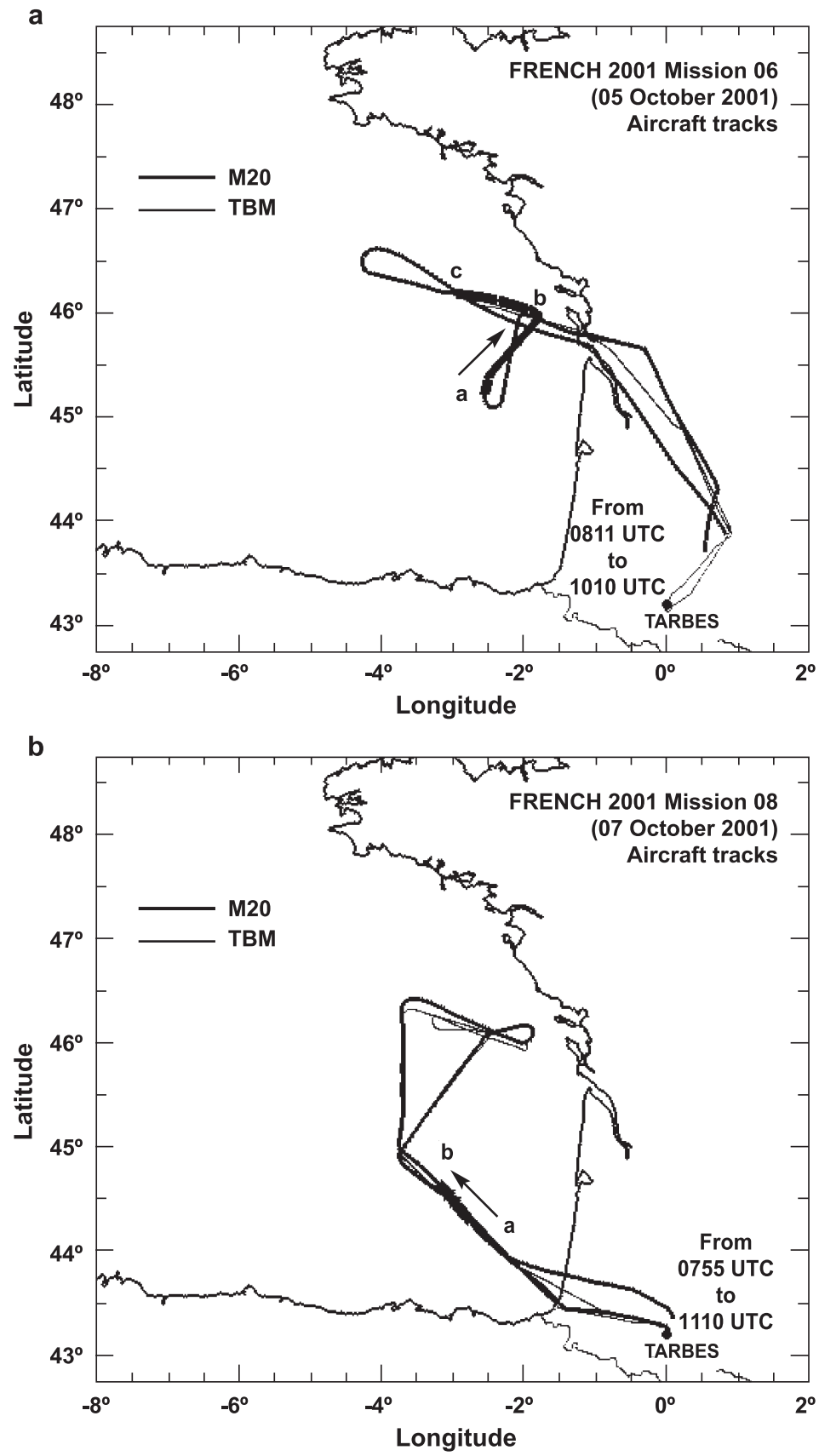

Fig. 2. (a) Flight tracks of Mystère 20 and TBM700 during Mission 06. The $\mathrm{a}-\mathrm{b}-\mathrm{c}$ leg in bold line concerns the more specific studied part. (b) Flight tracks of Mystère 20 and TBM700 during Mission 08. The a-b leg in bold line concerns the more specific studied part. 

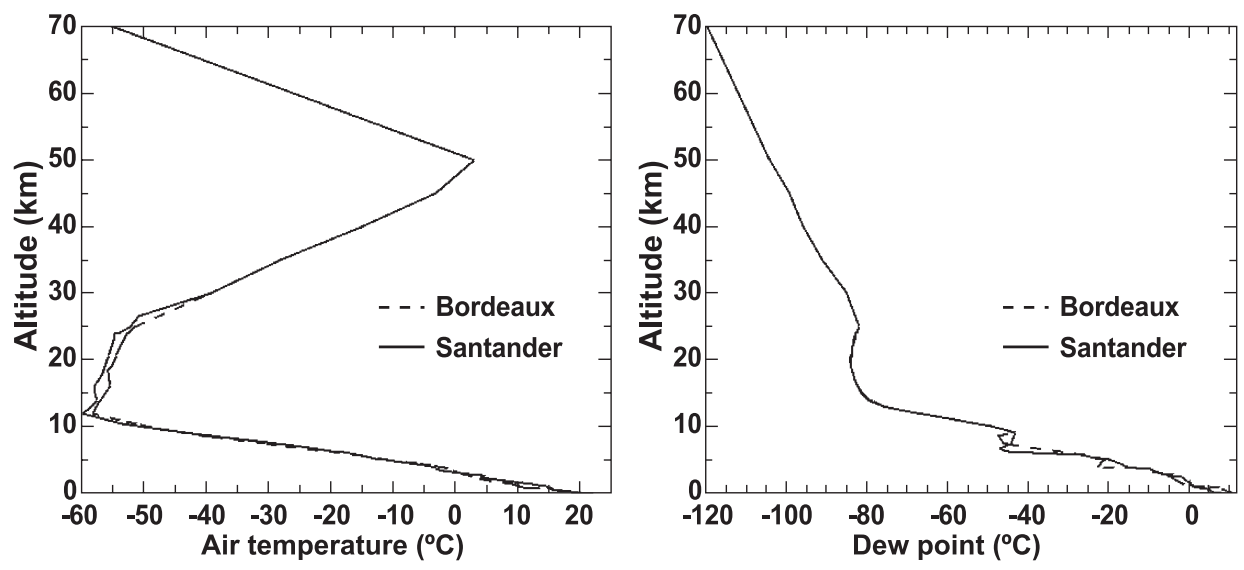

Fig. 3. Atmospheric profiles (air temperature and dew point temperature) obtained from radiosoundings at Bordeaux and Santander (see Fig. 2b) on October 7, 2001 (Mission 08).

A profile of depolarisation ratio for ice crystals $\Delta_{\mathrm{c}}$ is derived from a total depolarisation ratio for ice crystals and molecules:

$$
\Delta(p, z)=\frac{S_{\perp}(p, z)}{S_{/ /}(p, z)}
$$

The total depolarisation ratio is normalized to molecular depolarisation ratio $\Delta_{\mathrm{m}}=1.4 \%$ (Young, 1980), and corrected for this molecular contribution $\Delta_{\mathrm{m}}$ to derive $\Delta_{\mathrm{c}}$ (Sauvage et al., 1999).

During FRENCH, each lidar profile was averaged over a 2-km horizontal distance. For Mission 06 (October 5, 2001), lidar backscattering coefficient and depolarisation ratio, corresponding to the bold a-b-c line in Fig. 2a, are reported in Fig. 4a and b, respectively. The $\mathrm{a}-\mathrm{b}$ leg was performed between 0853 and 0900 UTC; point $\mathrm{c}$ was reached at 0910 UTC. The $\mathrm{a}-\mathrm{b}-\mathrm{c}$ leg was about $220 \mathrm{~km}$ in length.

From these figures, five regions are evidenced, and three types of cloud characteristics are clearly identified:

Low depolarisation ratio in regions I and IV.

Large depolarisation ratio in regions III and V.

Transition regions (regions 2 between I-III and III-IV).

In order to interpret this behaviour, backscattering coefficient and depolarisation ratio have been simulated with IHM model (C.-Labonnote et al., 2001) which is a microphysical model coherent with spatial measurements from ADEOS/POLDER in the visible domain. Results of these simulations are presented in Fig. 5 as function of the aspect ratio of the crystals.

For clouds composed of spheres, simulations using Lorenz-Mie theory show a low depolarisation ratio (in fact $\Delta_{\mathrm{c}}=0$ for spherical particles), and a high value of the backscatter to extinction ratio $k$. 
a

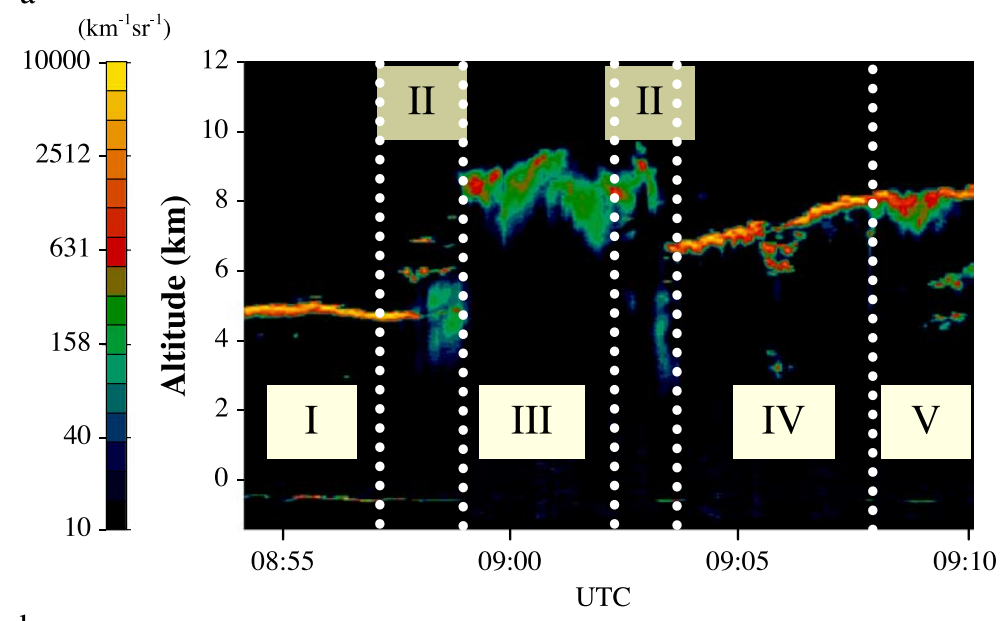

b

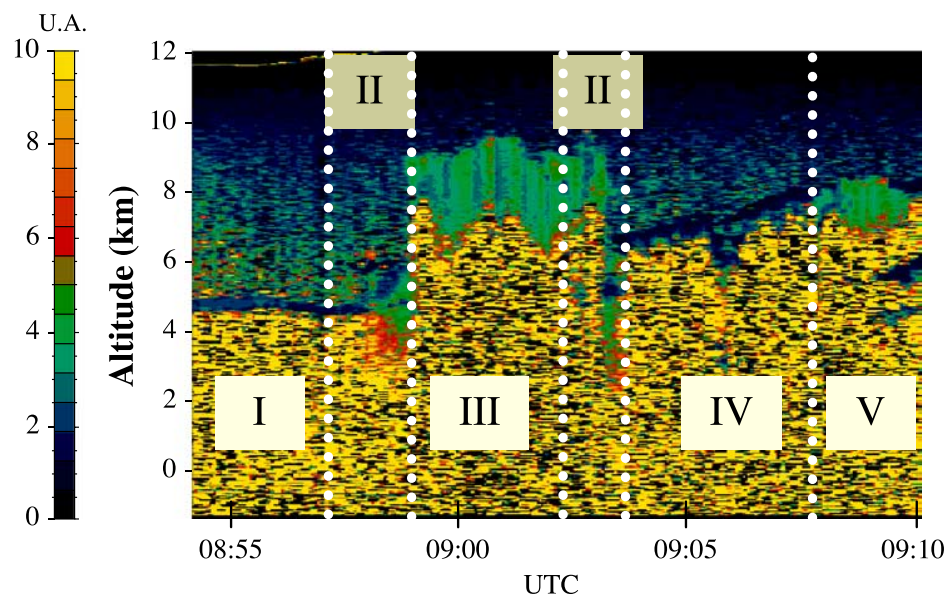

Fig. 4. (a) Mission 06 (10/05/2001) lidar backscattering coefficient $\beta$ from 0853 to 0910 UTC. (b) Mission 06 (10/ 05/2001) lidar depolarisation ratio from 0853 to 0910 UTC.

For clouds composed of ice crystals, $\Delta_{\mathrm{c}}$ is high (could be reach $30 \%$ ), and $k$ is weak (with a maximum value of $0.03 \mathrm{sr}^{-1}$ ).

In Fig. 4, regions I and IV exhibit all the features of clouds mainly composed of spherical particles (low depolarisation ratio). On the other hand, regions III and V exhibit the features of clouds composed of ice crystals (large depolarisation ratio). Moreover, the large values of the lidar backscattering coefficient in regions I and IV, and its low values in regions III and V, are typical of water clouds and ice clouds, for which the particle number density is generally high and low, respectively. A thermodynamical water phase change (liquid water to ice) is clearly evident between regions IV and V: The cloud top being almost constant, nevertheless one can see the transition from a low value of the depolarisation ratio to a high value, corroborated by a transition between a high value of lidar backscattering coefficient to a low value. 

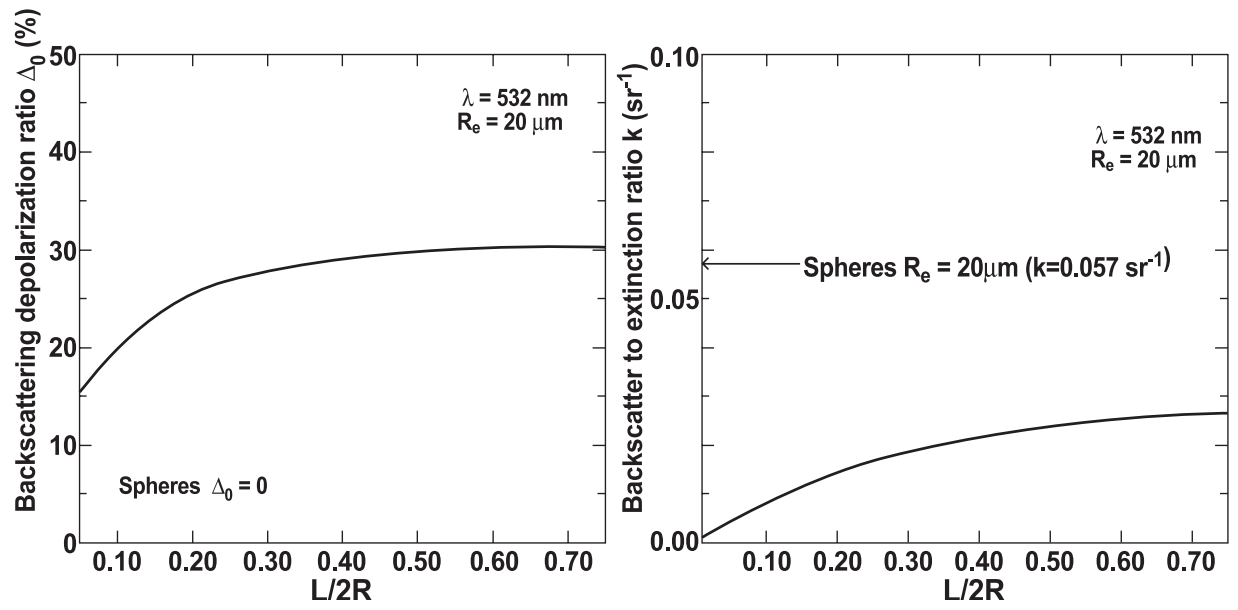

Fig. 5. Example of simulation of backscattering depolarisation ratio, and backscatter to extinction ratio as function of the aspect ratio of the particles.

\subsection{CLIMAT-AV}

The M-20 was equipped with a thermal infrared radiometer CLIMAT-AV (Conveyable Low-noise Infrared radiometer for Measurements of Atmosphere and ground surface Targets-Airborne Version) (see Legrand et al., 2000; Brogniez et al., 2003). CLIMAT looked downward to measure upward infrared radiance, using a 7-Hz sampling frequency, within a 50-mrad field of view, corresponding to a footprint of about 50-m diameter at a 1$\mathrm{km}$ range. The radiometer is composed of a frontal lens whose useful diameter is 11.80 $\mathrm{mm}$. A gilded retractable mirror is located in front of the optical head. Radiances are measured simultaneously in three spectral regions: 8.7, 10.8, and $12 \mu \mathrm{m}$, respectively named Ch1, Ch2, and Ch3 (see Fig. 6). They correspond to the spectral band pass of the infrared radiometer IIR on board the spaceborne platform CALIPSO, which is a component of the future AQUA-Train project. The accuracy on brightness temperature measurements derived from CLIMAT is of the order of $0.05 \mathrm{~K}$ in the three channels, with an integration time of $160 \mathrm{~ms}$.

Infrared radiance, integrated in the filter band pass of channel $i$, is given by:

$$
L_{\mathrm{i}}(T)=\frac{\Delta C_{\mathrm{i}}}{\sigma_{\mathrm{i}}}+L_{\mathrm{i}}^{\mathrm{m}}\left(T_{\mathrm{c}}\right),
$$

where $\sigma_{\mathrm{i}}$ is the radiometer sensitivity, $L_{\mathrm{i}}^{\mathrm{m}}$ is the radiance emitted by the radiometer cavity at temperature $T_{\mathrm{c}}, \Delta C_{\mathrm{i}}$ is the difference, in counts, between the signal coming from the target at brightness temperature $T$, and the signal obtained when the mirror shuts the radiometer cavity. For a given channel $\mathrm{i}$, the radiance $L_{\mathrm{i}}(T)$ is accurately fitted (better than $0.005 \%$ ) with the temperature $T$, via the empirical parameters $\alpha_{\mathrm{i}}, \beta_{\mathrm{i}}, \gamma_{\mathrm{i}}$, and $\delta_{\mathrm{i}}$, by the easily inverted relation:

$$
L_{\mathrm{i}}(T)=\frac{\alpha_{\mathrm{i}}}{e^{\beta_{\mathrm{i}} / T_{\mathrm{i}}}-\delta_{\mathrm{i}}}
$$




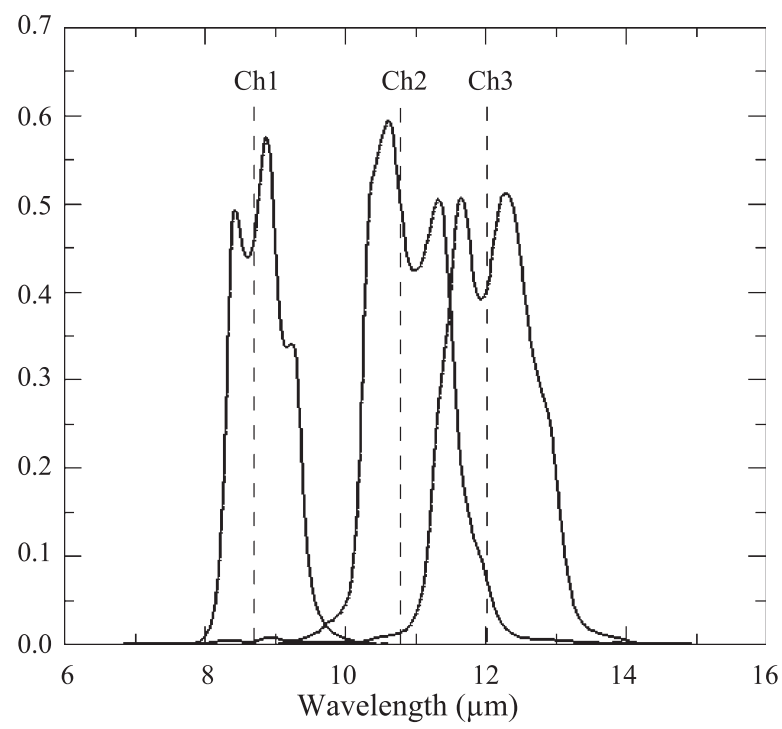

Fig. 6. Spectral band pass of the CLIMAT radiometer.

So the measurement of $\Delta C_{\mathrm{i}}$, and the knowledge of the cavity temperature $T_{\mathrm{c}}$, allows for an accuracy brightness temperature (BT) of the target.

Fig. 7 presents the upward brightness temperature of the observed cloud in Ch2 $(11-\mu \mathrm{m}$ channel) for the $a-b-c$ leg of Mission 06. This figure shows that:

- Regions III and V present low brightness temperatures (of the order of $-30{ }^{\circ} \mathrm{C}$ ) with thin optical thickness and high value of depolarisation ratio. The emitting temperature of this cloud region is of the order of $-35{ }^{\circ} \mathrm{C}$. Thus, the presence of ice crystals as detected by the lidar is coherent with these very low temperature values.

- Cloud brightness temperatures observed in region I are of the order of $0{ }^{\circ} \mathrm{C}$ and the emitting temperatures values are around $-12{ }^{\circ} \mathrm{C}$. Region IV, excepted the part between 0905 and 0906 UTC, which corresponds to great variability of the cloud vertical structure, exhibits brightness temperatures as well as emitting temperatures that range between about -20 and $-30{ }^{\circ} \mathrm{C}$. Moreover, from lidar analysis, cloud regions I and IV are expected to be liquid water cloud areas. The presence of supercooled water droplets in regions I and IV as detected by the lidar is not inconsistent with the brightness temperature values measured by CLIMAT.

This simple analysis of the combination of lidar and infrared radiometer here allowed to provide evidence of the presence of ice crystals and supercooled water droplets.

\subsection{Polder}

During FRENCH, the airborne version of POLDER instrument was operated by the Laboratoire d'Optique Atmosphérique on board the M-20. This instrument measures the 


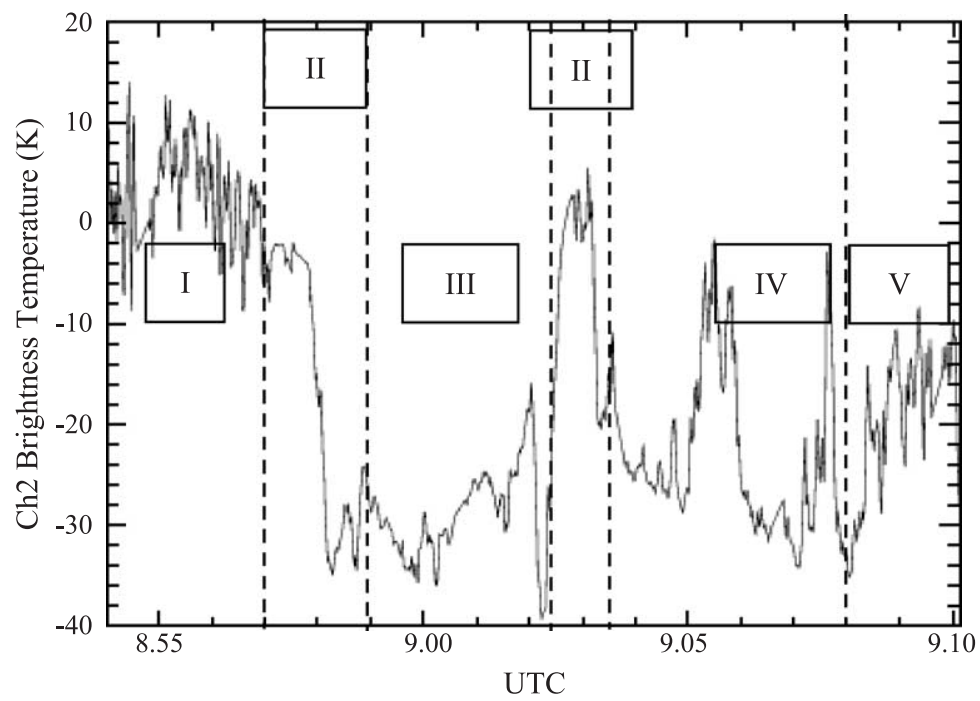

Fig. 7. Mission 06. Upward brightness temperature (in ${ }^{\circ} \mathrm{C}$ ) in the $11-\mu \mathrm{m}$ channel for the $\mathrm{a}-\mathrm{b}-\mathrm{c}$ leg.

intensity and the degree of linear polarisation of the scattered solar light. It is composed of a CCD matrix $(288 \times 242$ pixels, $32 \times 27-\mu \mathrm{m}$ per pixel $)$ which is set in the focal plane of a wide field-of-view telecentric optics (focal length of $3.565 \mathrm{~mm}$ ) and of a rotating wheel carrying five narrow band filters $(443,763,765,864$, and $910 \mathrm{~nm})$. During the FRENCH campaign, two channels (443 and $864 \mathrm{~nm}$ ) were equipped with analysers. The field-of-view of POLDER is $\pm 52^{\circ}$ along the aircraft track and $\pm 42^{\circ}$ cross track. For a target situated 1 $\mathrm{km}$ below the instrument, the footprint is $2.5 \times 1.8 \mathrm{~km}$ and the pixel size is $9 \times 8 \mathrm{~m}$. The airborne instrument is a simulator version of the multichannel radiometer on board the Japanese ADEOS (ADvanced Earth Observing System) platform launched in August 1996 (Deschamps et al., 1994) and onboard the ADEOS-2 platform launched in December 2002.

The present analysis of the cirrus cloud radiative properties is conducted using the 864-nm channel because the molecular contribution to the signals is weak and there is no noticeable absorption. From total $\left(L_{\mathrm{i}}\right)$ and polarized $\left(L_{\mathrm{i}}^{\mathrm{p}}\right)$ radiances measured by POLDER, where i stands for channel, bidirectional total and polarized reflectances are given by:

$$
\begin{aligned}
& \rho_{\mathrm{i}}\left(\theta_{\mathrm{s}}, \theta_{\mathrm{v}}, \varphi\right)=\frac{\pi L_{\mathrm{i}}\left(\theta_{\mathrm{s}}, \theta_{\mathrm{v}}, \varphi\right)}{E_{\mathrm{i}}^{\mathrm{s}} \cos \theta_{\mathrm{s}}} \\
& \rho_{\mathrm{i}}^{p}\left(\theta_{\mathrm{s}}, \theta_{\mathrm{v}}, \varphi\right)=\frac{\pi L_{\mathrm{i}}^{p}\left(\theta_{\mathrm{s}}, \theta_{\mathrm{v}}, \varphi\right)}{E_{\mathrm{i}}^{\mathrm{s}} \cos \theta_{\mathrm{s}}}
\end{aligned}
$$

where $E_{\mathrm{i}}^{\mathrm{s}}$ is the mean solar irradiance at the top of the atmosphere for channel $\mathrm{i}, \theta_{\mathrm{s}}$ is the solar zenith angle, $\theta_{\mathrm{v}}$ the viewing zenith angle, and $\varphi$ the relative azimuth angle.

Considering the October 5 flight-Mission $06-(\mathrm{a}-\mathrm{b}-\mathrm{c}$ leg), two sequences of POLDER measurements are displayed and two different cloudy scenes are clearly evidenced. 
Considering the October 5 flight-Mission 06- (a-b-c leg), two different types of cloudy scenes are clearly evidenced in regions I and IV, and in regions III and V. As example, three sequences of POLDER measurements corresponding to regions I, III and IV are displayed in Fig. 8.

(1) Fig. 8a and b presents the total and polarized reflectances, respectively, at 0855 UTC, i.e. corresponding to region I. The total reflectance shows a patchy structure, whereas in the polarized reflectance image, a cloud bow appears, which is characteristic of the presence of spherical particles in the cloud.

(2) At 0859 UTC, during the overflown of region III, the total reflectance presented in Fig. $8 \mathrm{c}$ shows a more uniform structure, whereas polarized reflectance image does not show a particular structure in Fig. 8d.

(3) Finally at 0907 UTC, during the overflown of the region IV, the total reflectance image (Fig. 8e) and the polarized reflectance image (Fig. 8f) display structural and angular characteristics similar to those observed in region I. The cloud top structures appear more complex than in region III and a clow bow is detected at top right of the polarized component image. The cloud bow is an angular phenomenon and its new position in the image is due to the change in flight heading.

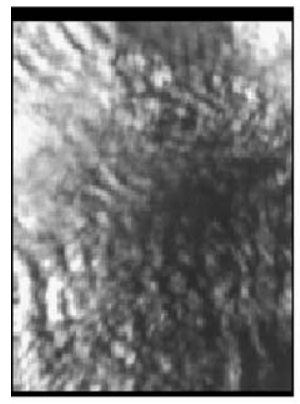

a

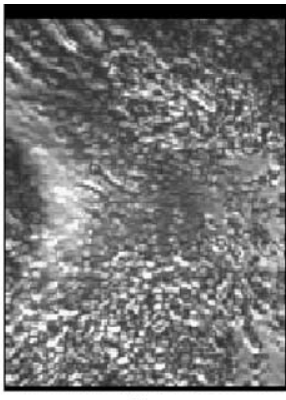

b

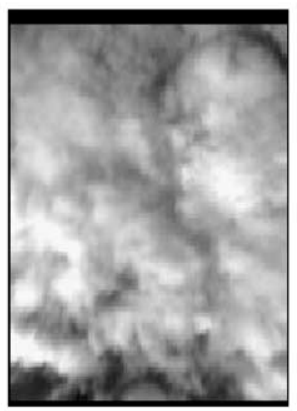

$\mathrm{e}$

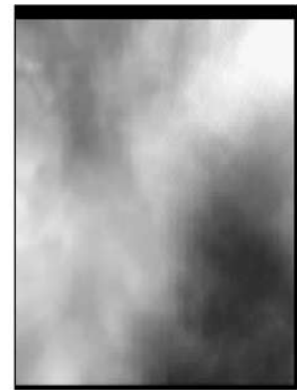

c

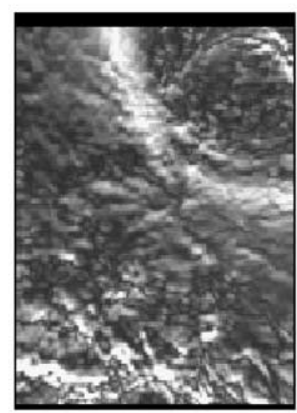

f

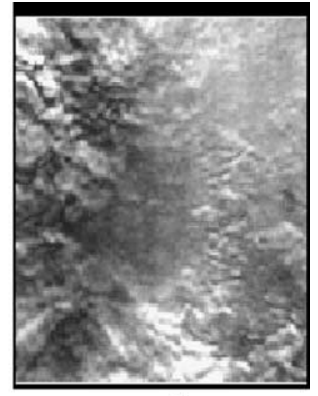

d

Fig. 8. POLDER images of total (a, $c$ and e) and polarized (b, $d$ and f) reflectances at $864 \mathrm{~nm}$. a and b stand for region I, $\mathrm{c}$ and $\mathrm{d}$ stand for region III, and e and $\mathrm{f}$ stand for region IV. 


\subsection{MINIMIR}

The airborne MINIMIR (Middle Infrared Radiometer) reflectance meter was operated by the Laboratoire d'Optique Atmosphérique on board the M-20. MINIMIR measures the spectral radiances and polarisation characteristics of the scattered solar light in the near and the middle infrared part of the spectrum.

The optical head of MINIMIR consists of a battery of nine separate optical cavities, the optical axis of all the cavities being parallel. Each cavity is equipped with a narrow spectral band pass filter. The filters are centred at $0.67,0.87,1.35,1.6$, and $2.2 \mu \mathrm{m}$ (see Fig. 9). The measurements of polarisation rate of reflected light are performed for the 1.6and 2.2- $\mu \mathrm{m}$ channels. As for POLDER, the measurements of polarisation rate require three identical cavities per channel, each of them being equipped with an analyser positioned $60^{\circ}$ one from each other.

The field of view of the instrument is about $20 \mathrm{mrad}$, corresponding to a footprint of about $20 \mathrm{~m}$ at a $1-\mathrm{km}$ range.

The optical axis of the instrument has a $20^{\circ}$ inclination with respect to the vertical reference of the aircraft, toward the rear of the aircraft. The heading, pitch and roll of the aircraft are taken into account in order to calculate the viewing zenith and azimuth angles.

The data provided by MINIMIR are: (i) bidirectional total reflectance $\rho_{\mathrm{i}}$ for $0.67,0.87$, and 1.35 , and (ii) bidirectional total and polarized reflectances ( $\rho_{\mathrm{i}}$ and $\rho_{1}^{\mathrm{p}}$, respectively) for 1.6 and $2.2 \mu \mathrm{m}$. The index i stands for any of the channels. The definitions of $\rho_{\mathrm{i}}$ and $\rho_{1}^{\mathrm{p}}$ are the same as for POLDER (see Eqs. (5a) and (5b)).

Fig. 10 shows the measurements of bidirectional reflectances at 870 and $1600 \mathrm{~nm}$, obtained from MINIMIR during the $\mathrm{a}-\mathrm{b}-\mathrm{c}$ leg of Mission 06, between 0853 and 0910 UTC.

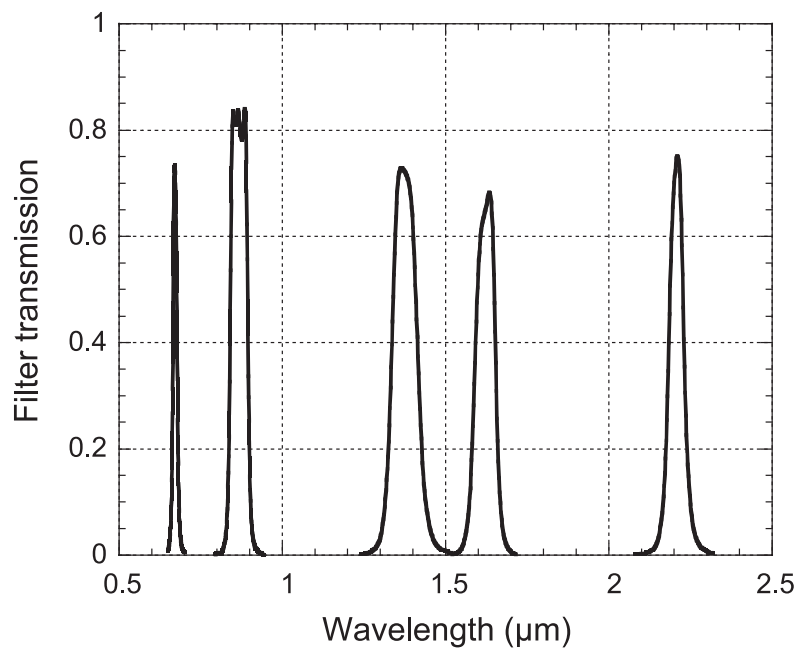

Fig. 9. Spectral band pass of MINIMIR. 
a

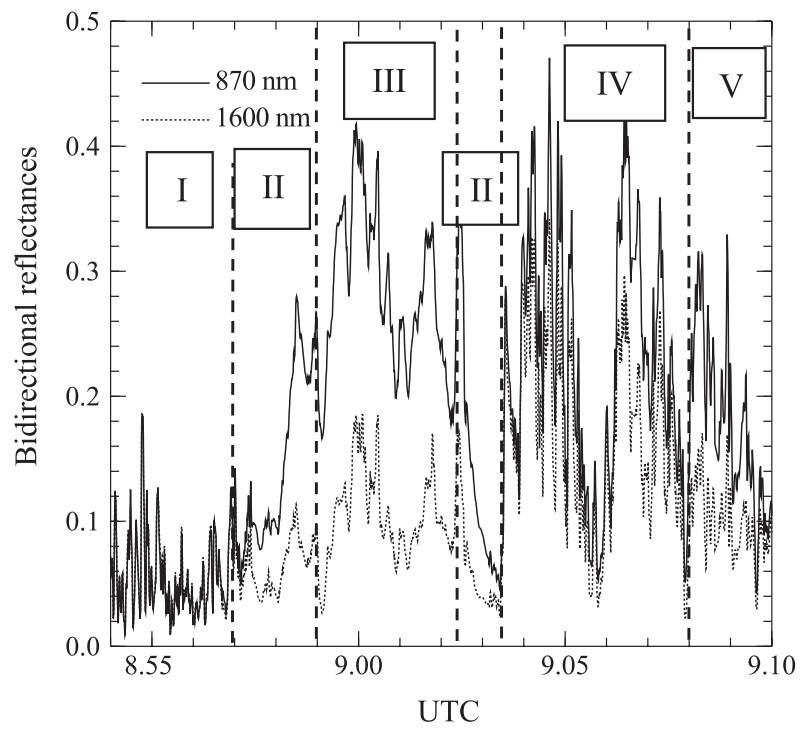

b

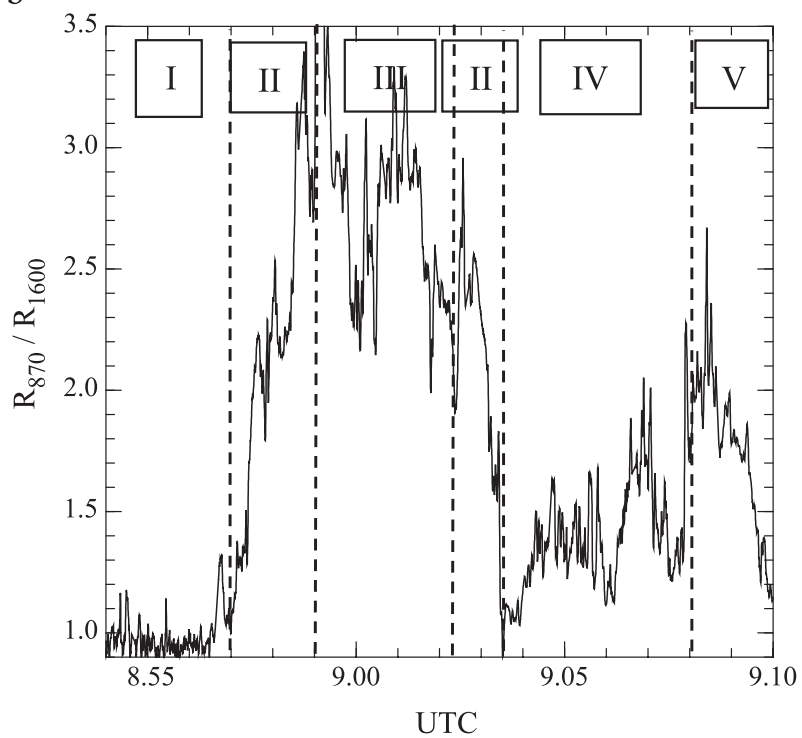

Fig. 10. (a) MINIMIR measurements at 870 and $1600 \mathrm{~nm}$ along the $\mathrm{a}-\mathrm{b}-\mathrm{c}$ leg of Mission 06. (b) Reflectance ratio at these two wavelengths.

Like from lidar and CLIMAT measurements, the three types of regions are also clearly identified from MINIMIR measurements on the same time ranges:

- Bidirectional reflectances, which are independent of wavelengths (region I) or weakly dependent on wavelengths (region IV). 


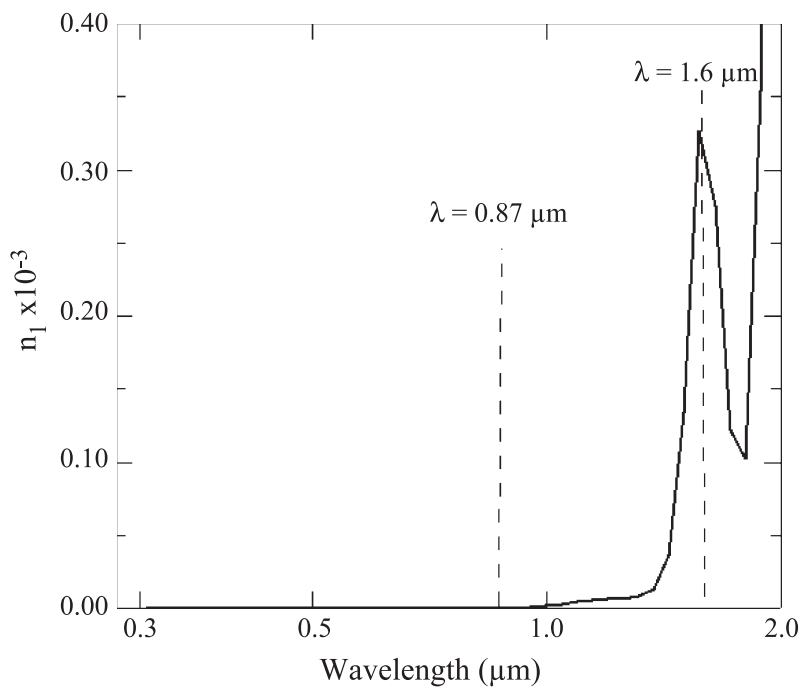

Fig. 11. Imaginary part of the refractive index of ice in the middle infrared domain.

- Bidirectional reflectances, which are larger in the channel 870 than in channel $1600 \mathrm{~nm}$ in regions III and $\mathrm{V}$.

- Transition regions II.

The cloud reflectance is almost independent of size of the cloud particles (ice crystals or liquid water droplets) at $870 \mathrm{~nm}$, since the extinction index of ice (or water) is negligible. On the contrary, cloud reflectance strongly depends on their size at 1600 $\mathrm{nm}$, since the extinction index of ice (or water) is important at $1600 \mathrm{~nm}$ (Warren, 1984) (Fig. 11).

In regions I and $\mathrm{IV}$, as 870 - and $1600-\mathrm{nm}$ bidirectional reflectances are not very different, there is little absorption by cloud particles, then one can expect that the cloud is composed of small particles.

In region III, the very large difference between the bidirectional reflectances may be due to very large cloud particle, i.e. ice crystals.

\section{Interest of combined use of remote sensing measurements for retrieving ice cloud microphysical properties - comparison with in situ measurements: Mission 08 case study (October 7, 2001)}

\subsection{Microphysics by remote sensing in the thermal infrared using synergy with lidar}

In the thermal infrared, the imaginary part of the refractive index $n_{\mathrm{e}}$ of ice is not negligible and strongly varies between 8 and $12 \mu \mathrm{m}$ (Fig. 12) (Warren, 1984). Consequently the brightness temperatures measured in the channels $\mathrm{Ch} 1, \mathrm{Ch} 2$, and $\mathrm{Ch} 3$ and centred on $8.7,10.8$, and $12 \mu \mathrm{m}$, respectively, which obviously depend on the cloud 


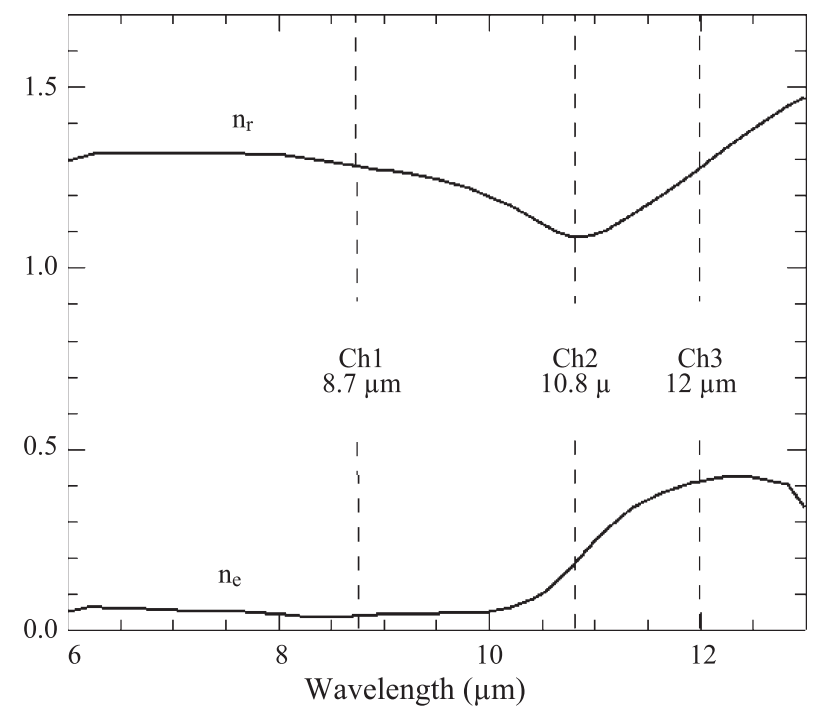

Fig. 12. Real $\left(n_{\mathrm{r}}\right)$ and imaginary part $\left(n_{\mathrm{e}}\right)$ of the refractive index of ice in the thermal infrared.

optical thickness, are expected to depend also of the mean effective size of ice crystals that compose the observed cirrus cloud (Inoue, 1985; Wu, 1987; Parol et al., 1991).

According to these authors, the Brightness Temperature Differences (BTD) between two channels depend on the cloud microphysical properties and cloud optical thickness, and BTD are more important for thin cirrus clouds than for thick clouds or clear sky areas. The link between $\mathrm{BTD}_{i j}=\mathrm{BT}_{i}-\mathrm{BT}_{j}$, (where $i$ or $j$ stands for radiometer channel number), and the brightness temperature for a given channel $\mathrm{BT}_{i}$ or $j$ depends on the cloud microphysics. In order to interpret the outgoing brightness temperature, and the BTD measured by CLIMAT above the cirrus cloud, the FastRad code (Dubuisson et al., 1996) based on a scattering method using Discrete Ordinates was used (Stamnes et al., 1988).

The spectroscopic database of the radiance code includes HITRAN-2000 and the continuum parameterisation for water vapour absorption with the $\mathrm{CKD}_{2.4}$ water vapour model (Tobin et al., 1999; Giver et al., 2000; Rothman et al., 2001). If necessary, the FastRad code can consider multilayered clouds, for example the case of a cirrus deck above a low-level liquid cloud. The input parameters of FastRad are:

(i) Temperature and humidity profiles of the atmosphere, here given from balloon radiosounding.

(ii) Sea surface temperature: The sea surface temperature is adjusted in order to make calculations and measurements in agreement in case of clear sky.

(iii) Aerosol properties: Optical properties and number density profile of standard maritime aerosols have been used (WCP, 1986).

(iv) Altitude and geometrical thickness of cloud deduced here from lidar measurements are installed on board M-20. 
(v) Single scattering properties of cloud particles. For liquid phase clouds (i.e. spherical particles), Lorenz-Mie theory is used. For solid phase clouds (i.e. ice crystals), two populations of particles have been considered: pristine hexagons and aggregates randomly oriented. A combination of T-matrix (hexagonal columns, circular cylinders) and complex angular momentum approximation is used to calculate scattering properties of pristine hexagonal ice crystals (Baran et al., 2001). The above cited database is used.

Simulation of scattering by ice aggregates is made using a size-shape distribution of circular ice cylinders (Baran, 2003).

Then, for a well-documented cirrus case, FastRad code can simulate radiometric measurements. The first stage of the BDT method consists in finding a part of flight leg showing a strong variability of brightness temperatures, i.e. a strong variability of optical thickness, from clear sky to thick cloud. Fig. 13a shows, as function of time, a lidar backscattering profile corresponding to the $\mathrm{a}-\mathrm{b}$ leg indicated in Fig. $2 \mathrm{~b}$.

The zone between 0918 and 0922 UTC corresponds to a leg of about $68-\mathrm{km}$ long. It is a transient zone between clear sky and a thick high-level cloud (altitude of $9.5 \mathrm{~km}$ ) and, simultaneously, a second layer of low-level cloud (altitude of $3 \mathrm{~km}$ ). The horizontal black line represents the TBM flight level at an altitude of about $9600 \mathrm{~m}$.

Fig. 13b shows the CLIMAT Channel 1 brightness temperature, as a function of time, for this selected zone. The warm part (approximately $+15{ }^{\circ} \mathrm{C}$ ) until 0919 UTC corresponds to clear sky, whereas the cold part (approximately $-12{ }^{\circ} \mathrm{C}$ ) corresponds to the thicker part of the ice cloud.

This cloud variability can be reproduced using FastRad code by variation of the number density of ice crystals, i.e. by variation of the cloud optical thickness. A low level cloud composed of water droplets is situated under the cirrus cloud. The cloud top temperature of the cirrus is fixed to $-42{ }^{\circ} \mathrm{C}$ according to the radiosounding temperature profile (see Fig. 3).

Fig. $13 \mathrm{c}$ and $\mathrm{d}$ shows the radiometric measurements of the difference $\mathrm{BT}_{1}-\mathrm{BT}_{2}$ as function of $\mathrm{BT}_{1}$. Simulations using hexagonal crystals and aggregates are superimposed, the effective radii of these particles being adjusted to fit the measurements.

For the $\mathrm{a}-\mathrm{b}$ leg, brightness temperature measurements performed by the CLIMAT radiometer are consistent with results of simulations using pristine hexagonal ice crystals or aggregates. Concerning hexagonal crystals, the effective radii $R_{\text {eff }}$ are in the [20.8-30.8 $\mu \mathrm{m}]$ range, whereas for aggregates, the agreement with measurements is obtained with effective radii slightly bigger than with hexagonal particles, in the [22.1-33.6 $\mu \mathrm{m}]$ range. Taking into account the important dispersion of measurements, probably due for a part to the cloud heterogeneity, the small discrepancy in the retrievals may be considered as not significant.

\subsection{Microphysics by remote sensing in the middle infrared}

Fig. 14 shows the measurements of bidirectional reflectances at 870 and $1600 \mathrm{~nm}$, obtained from MINIMIR during the $\mathrm{a}-\mathrm{b}$ leg of Mission 08, between 0917 UTC and 0922 


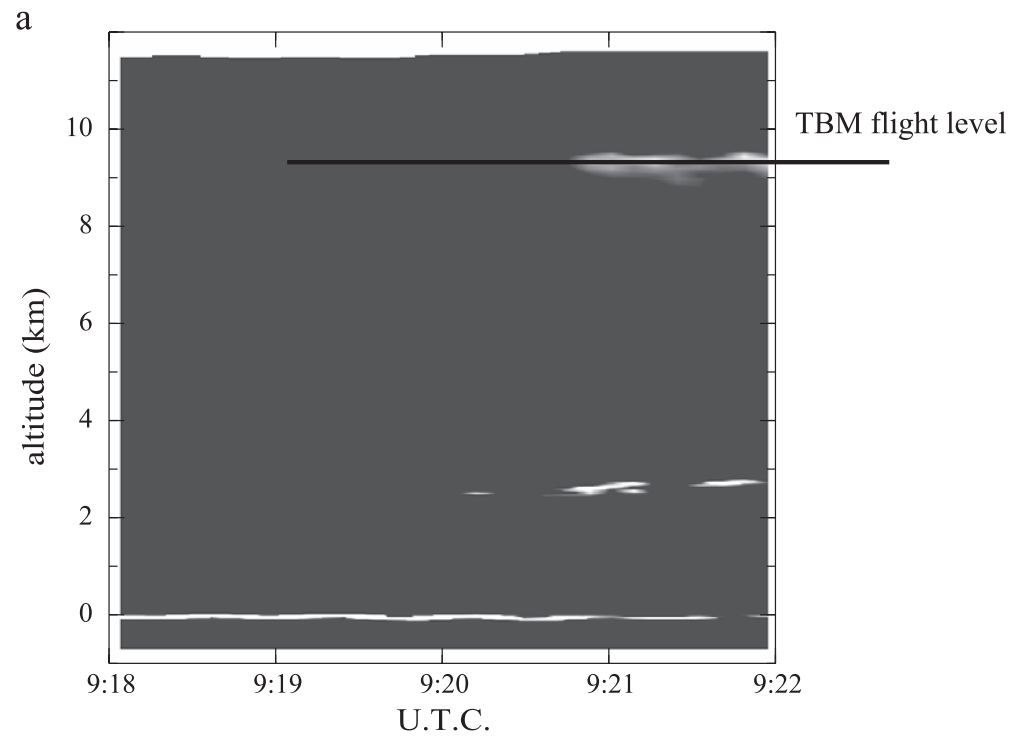

b

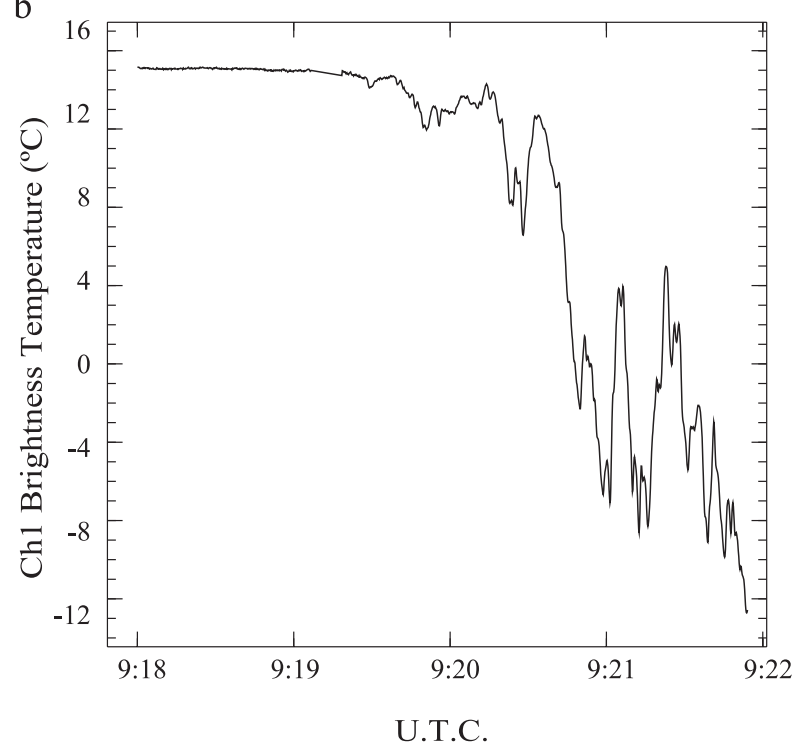

Fig. 13. (a) a-b leg of Mission 08. Lidar backscattering profile (the grey scale is arbitrary). (b) Mission 08 . Upward brightness temperature measured in CLIMAT Channel 1 along the $a-b$ leg. (c) Measurements of the difference $\mathrm{BT}_{1}-\mathrm{BT}_{2}$ as function of $\mathrm{BT}_{1}$ along the $\mathrm{a}-\mathrm{b}$ leg. Simulations using hexagonal ice crystals are superimposed. (d) Measurements of the difference $\mathrm{BT}_{1}-\mathrm{BT}_{2}$ as function of $\mathrm{BT}_{1}$ along the $\mathrm{a}-\mathrm{b}$ leg. Simulations using aggregates crystals are superimposed. 


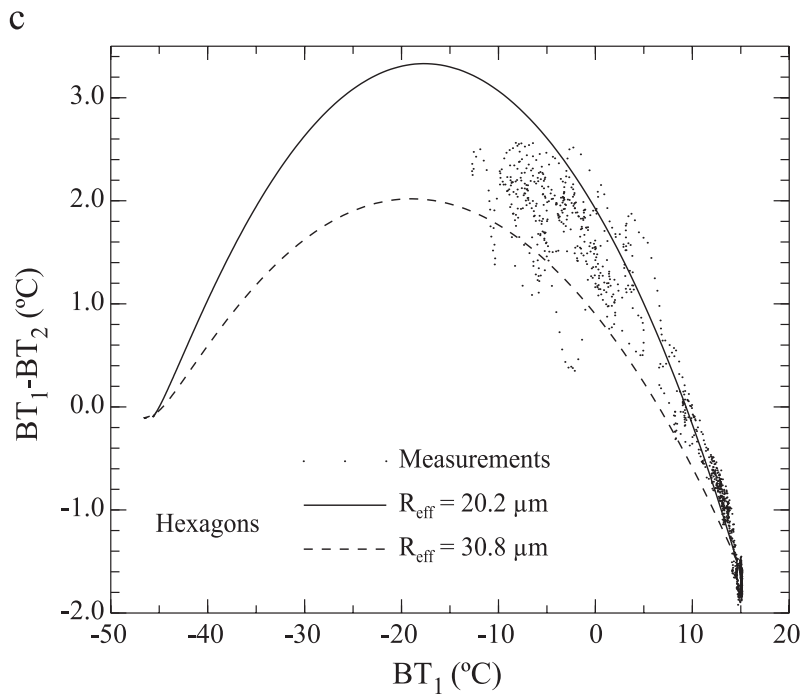

$\mathrm{d}$

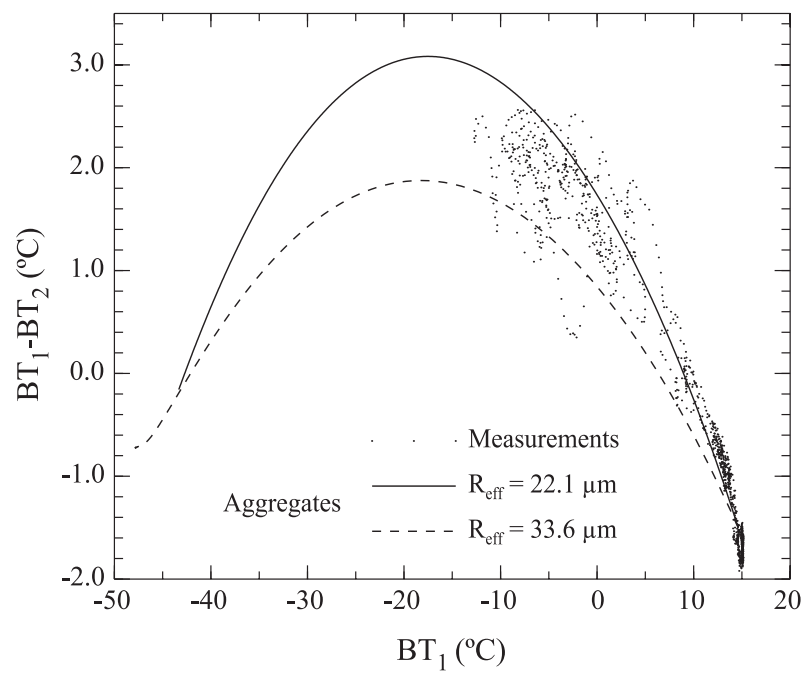

Fig. 13 (continued).

UTC. Along this leg, bidirectional reflectances at $870 \mathrm{~nm}$ were always larger than 1600 $\mathrm{nm}$ reflectances, due to the presence of large particles in the cloud.

During this leg, the direction of the incident solar beam was characterized by the solar zenith angle $\theta_{\mathrm{s}}=62.3^{\circ}$, and by the solar azimuth angle $\varphi_{\mathrm{s}}=131.7^{\circ}$. The viewing direction was characterized by the viewing zenith angle (about $\theta_{\mathrm{v}}=20^{\circ}$ ), and by the viewing azimuth angle (about $\varphi_{\mathrm{v}}=310^{\circ}$, taking into account the aircraft attitude). These parameters are the input of the radiative transfer code Adding-Doubling (De Haan et al., 1986) to simulate reflectances above a cirrus cloud with varying optical thickness. 


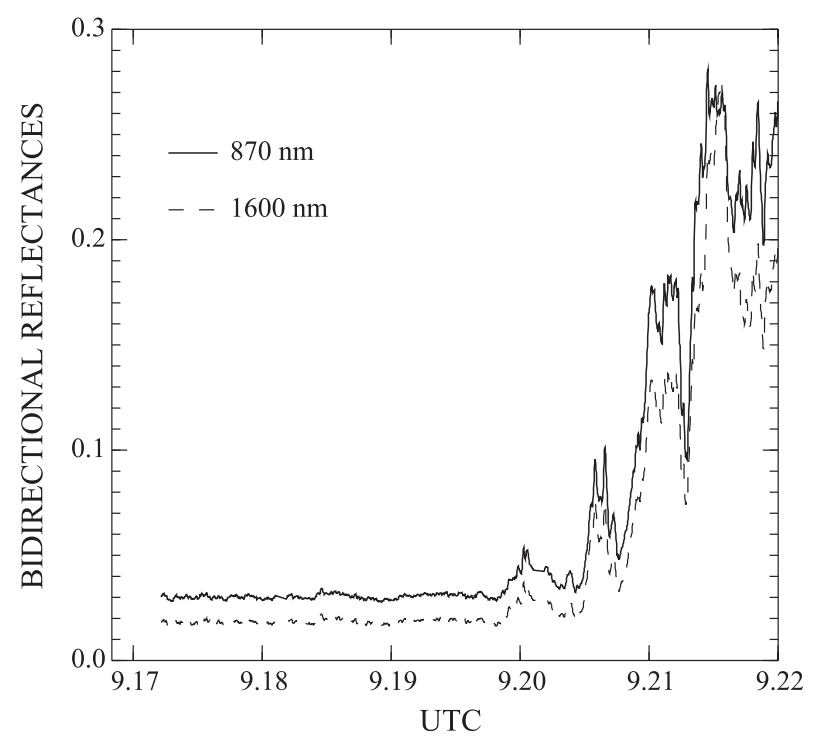

Fig. 14. MINIMIR measurements at 870 and $1600 \mathrm{~nm}$ along the $\mathrm{a}-\mathrm{b}$ leg of Mission 8 .

Ice is known to be absorbing at $1600 \mathrm{~nm}$, while it is transparent at $870 \mathrm{~nm}$ (see Fig. 11), and the analysis of the differences of the reflectances at those two wavelengths combined with modelling could allow to retrieve the effective dominating size of ice crystals in cirrus clouds. For the selected scene, we have compared MINIMIR bidirectional reflectance measurements at 870 and $1600 \mathrm{~nm}$ and theoretical simulations.

Simulations of ice cloud reflectivities have been performed by using a theoretical scattering model of ice cloud crystals called Inhomogeneous Hexagonal Monocrystal Model (IHM). From C.-Labonnote et al. (2001), this model is quite appropriate to simulate ice cloud reflectivities. It consists in computing the scattering light by an ensemble of randomly oriented hexagonal ice crystals containing spherical impurities of soot and air bubbles. It is achieved by using a combination of ray tracing technique, Lorenz-Mie theory and Fraunhofer diffraction. This model allows to calculate the six independent elements of the scattering matrix. The crystals are characterised by their length $L$ and radius $R$, or by the aspect ratio $L / 2 R$ and the radius $R_{\mathrm{V}}$ of volume equivalent spherical particle. The radii of air bubbles or impurities are assumed to follow a gamma standard distribution characterised by an effective radius and an effective variance. The subsequent internal scattering events are characterised by their mean free path length. The effective radius of crystals in terms of scattering is defined by:

$$
R_{\text {eff }}=\frac{3}{4} \frac{(\text { particle volume })}{\text { (mean particle projected area) }}
$$

Fig. 15 shows a comparison between reflectance measurements at 1600 and $870 \mathrm{~nm}$. Results of simulations performed with different effective radii of IHM crystals are superimposed.

Along the a-b leg of Mission 08, IHM ice crystals with $R_{\text {eff }}$ slightly smaller than $35 \mu \mathrm{m}$ stand as good candidates for restitution of the MINIMIR measurements on average. 


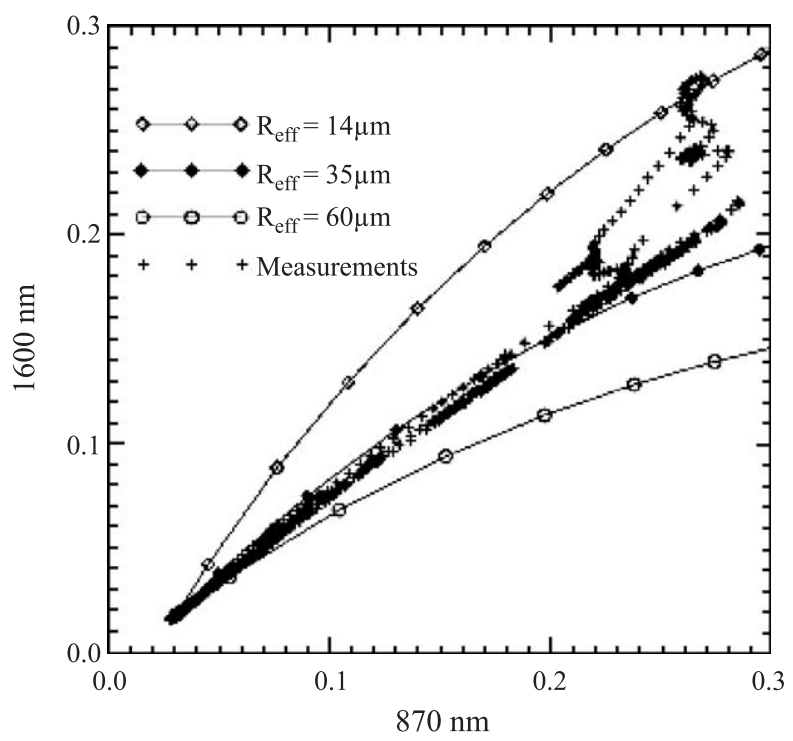

Fig. 15. Comparison between MINIMIR measurements and simulations during the $a-b$ leg.

However, the observed variability of $1600-\mathrm{nm}$ reflectance for high $870-\mathrm{nm}$ reflectance values highlights the presence of relatively small cloud particles with $R_{\text {eff }}$ down to about $14 \mu \mathrm{m}$. These later values are verified to be associated to the presence of a low level cloud seen by the instrument between 0920 and 0921 UTC.

\subsection{Consistency of remote sensing retrievals}

The retrievals of effective radius of ice crystal in cirrus clouds from CLIMAT measurements in the thermal infrared, and from MINIMIR measurements in the middle infrared, lead to almost the same values. For both cases, these retrievals need input microphysical models to simulate single scattering properties of ice crystals. In the case of middle infrared measurement interpretations, we have used the Inhomogeneous Hexagonal Monocrystal (IHM) model, which has been tested very satisfactorily regarding ADEOS/ POLDER measurements in the visible part of the solar spectrum (C.-Labonnote et al., 2001). Nevertheless, our calculation method of optical properties of IHM does not work in the thermal infrared. That is why, in the thermal infrared domain, we have tested two other models: Pristine Hexagonal Model and Aggregate crystal model (Baran et al., 2001; Baran, 2003). However, the two mean effective radii derived from these two infrared models are very close.

In the visible-middle infrared part of the spectrum, the imaginary part value of the refractive index is very low ( $\approx 0$ to $0.310^{-3}$ ) compared to its value in thermal infrared ( $\approx 0.1$ to 0.4 ); consequently, ice is much more transparent in shortwave than in longwave. Inside IHM crystals, two subsequent internal scattering events, due to impurities, are characterized by a free path length defined by $\ell=-\langle\ell\rangle \ell \mathrm{n} R$, where $\langle\ell\rangle$ is the mean free path length and $R$ is a random number within the range $[0,1]$. On the one hand, from 
C.-Labonnote et al. (2001), adequate IHM model being characterised by $\langle\ell\rangle=15 \mu m$, incident shortwave photons can reach easily internal impurities and are subject to scattering. Consequently, in shortwave, optical properties of IHM and Pristine Hexagonal ice crystals are very different (C.-Labonnote et al., 2001). On the other hand, the photon intensity follows a decreasing exponential law which is $\exp \left(-\frac{4 \pi}{\lambda} n_{\mathrm{e}} d\right)$ where $d$ is the path within the crystal ( $\lambda$ being the wavelength, $n_{\mathrm{e}}$ the imaginary part of the refractive index). In thermal infrared, for $d=\langle\ell\rangle$, the photon intensity is only lower than $2 \%$ of the incident value, and IHM optical properties should be very close to the Pristine Hexagonal ice crystals ones.

Then, the combined microphysical models (IHM model in visible-middle infrared)+ (Pristine Hexagonal crystals in thermal infrared) can constitute a good coherent microphysical model to interpret measurements in the whole spectrum.

Fig. $13 \mathrm{c}$ and d has shown that Aggregate ice crystals are consistent with measurements in thermal infrared. The validity of this model in the visible and middle infrared wavelength domains should be very interesting to investigate.

\subsection{Validations from in situ microphysical measurements}

(1) The PMS OAP-2D2-C optical probe (Optical Array Probe from Particle Measuring System, Boulder, Colorado) onboard the TBM-700, which provides two-dimensional images of particles with mean size from 50 to $800 \mu \mathrm{m}$, unfortunately was out of order during Mission 08.

(2) A polar nephelometer described in details in Crépel et al. (1997), and Gayet et al. (1997) was installed on board the TBM 700. It is designed to measure the differential scattering cross section $\sigma^{\mathrm{d}}(\Theta)$ of light scattered by an ensemble of cloud particles as a function of the scattering angle $\Theta$ (over a mean size range from a few micrometers to about $800 \mu \mathrm{m})$. Due to the optical design, the scattering angles are sampled from $15^{\circ}$ to $155^{\circ}$. Fig. 16 presents averaged measurements of $\sigma^{\mathrm{d}}(\Theta)$ obtained when TBM 700 flew inside the cirrus cloud, approximately below the M20 along the a-b leg, at an altitude of about $9600 \mathrm{~m}$, in the upper part of the cloud (see Fig. 2b).

Microphysical properties of clouds can be derived from this device measurements using an inversion method, as the behaviour of $\sigma^{\mathrm{d}}(\Theta)$ strongly depends itself on the microphysical properties of clouds. It was already shown that the information contained in the polar nephelometer measurements is sufficient to restore component composition and particle size distribution (Jourdan et al., 2003).

The iterative inversion method developed by Oshchepkov et al. (2000), using physical modeling of the scattered light, is based on a bi-component (ice spheres and hexagonal ice crystal) representation of cloud composition and uses the nonlinear least square fitting of $\sigma^{\mathrm{d}}(\Theta)$ using smoothness constraints on the desired particle size distributions. The microphysical model used in this study is rather simple but remains flexible and sufficient to take into account cloud composition and size effects. The method needs to specify a lookup table containing $\sigma^{\mathrm{d}}(\Theta)$ of each individual ice crystal. The differential scattering cross sections $\sigma^{\mathrm{d}}(\Theta)$ of spherical crystals follows from classic Lorenz-Mie. The scattering 


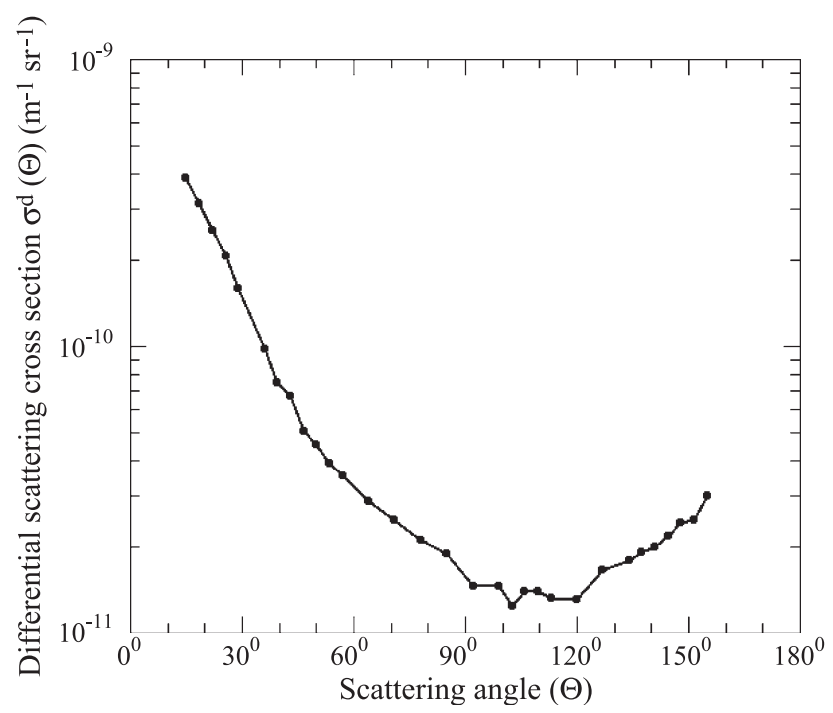

Fig. 16. Averaged polar nephelometer measurements obtained inside the cirrus along the $a-b$ leg (Mission 08).

patterns of spatially randomly oriented hexagonal crystals, with aspect ratio equal to unity, are computed using an improved geometric-optics model (Yang and Liou, 1996). In the setting up of the lookup table, we define an equivalent size, $R_{\text {eq }}$, of ice crystal through the radius of an area-equivalent circle whose area is equal to the ice crystal cross-section randomly oriented.

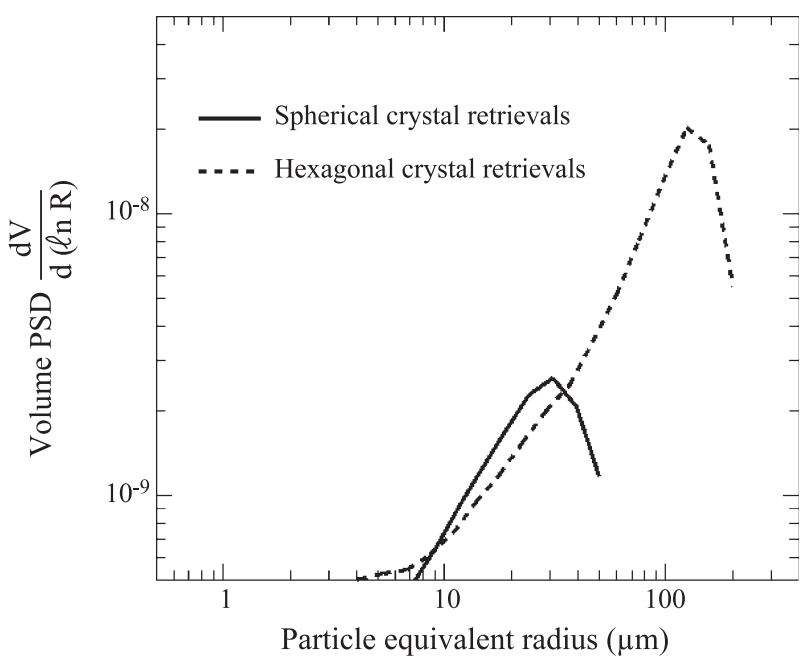

Fig. 17. Inversion results, in terms of particle size distribution (PSD), corresponding to the nephelometer measurements along the $\mathrm{a}-\mathrm{b}$ leg (Mission 08) in the upper part of the cirrus cloud. 
Table 3

Microphysical parameters retrieved from polar nephelometer measurements

\begin{tabular}{llll}
\hline Microphysical parameters & Ice spheres & Hexagonal ice crystals & Spheres and hexagonal ice crystals \\
\hline$N\left(\mathrm{~cm}^{-3}\right)$ & 13.4 & 5.9 & 19.4 \\
TWC $\left(\mathrm{g} \mathrm{m}^{-3}\right)$ & 0.0036 & 0.0183 & 0.0219 \\
$R_{\text {eff }}(\mu \mathrm{m})$ & 11.35 & 42.74 & 30.24 \\
\hline
\end{tabular}

(a-b leg of Mission 08).

The inversion results, in terms of volume particle size distribution, are displayed in Fig. 17.

The ability of the inversion technique to discriminate the contribution of the components leads to the retrieval of representative particle size distributions. However, the limited information content of the measured differential scattering cross sections prevents the accurate retrieval of numerous parameters characterizing complex ice crystal shapes or surface roughness. It only allows us to retrieve the cloud phase composition, its particle size distributions and aspect ratio of the assumed hexagonal ice crystals.

Accordingly, the use of our microphysical model permits the retrieval of microphysical parameters corresponding to some average cloud microphysical characteristics that will lead to realistic optical behavior of the cloud.

Thus, we obtain the particle number density $(N)$, the total water content (TWC), and the effective radius of cirrus particles $\left(R_{\mathrm{e}}\right)$, for ice spheres, hexagonal ice crystals, and for a composition of the two species, respectively. The equivalent effective radius for the composition of the two species is calculated using the following expression:

$$
R_{\mathrm{e}}=\frac{\sum_{s=1}^{2} \int_{0}^{\infty} \frac{1}{R_{\mathrm{eq}_{\mathrm{s}}}} \frac{\mathrm{d} V_{\mathrm{s}}}{\mathrm{d} \ell n R_{\mathrm{eq}_{\mathrm{s}}}} \mathrm{d} \ell n R_{\mathrm{eq}_{\mathrm{s}}}}{\sum_{s=1}^{2} \int_{0}^{\infty} \frac{1}{R_{\mathrm{eq}_{\mathrm{s}}}^{2}} \frac{\mathrm{d} V_{\mathrm{s}}}{\mathrm{d} \ell n R_{\mathrm{eq}_{\mathrm{s}}}} \mathrm{d} \ell n R_{\mathrm{eq}_{\mathrm{s}}}}
$$

where the index $s=1,2$ stands for ice droplets and ice crystals, respectively.

The results are summarized in Table 3.

\section{Discussion and conclusion}

In this paper, we have presented the first results of combination between the various remote sensor instruments operating during FRENCH/DIRAC. These measurements constitute an extremely valuable data set for radiative transfer studies at the mesoscale. The data set includes different measurements: (i) in situ microphysics measurements using the polar nephelometer, (ii) upward infrared radiative measurements collected above the cirrus cloud by the CLIMAT radiometer, (iii) airborne lidar data with polarisation capabilities, (iv) airborne POLDER bidirectional total and polarized reflectances, and (v) middle infrared measurements with MINIMIR reflec- 
tance meter. As a summary, this paper presents the extented data set collected during the FRENCH/DIRAC campaign, and the manner in which the different data have been processed at time.

A preliminary analysis conducted on two high priority mission cases leads to the first following conclusion:

(1) A data set collected during case study on 05 and 07 October 2001 allows us to present as complete as possible a description of cirrus clouds at the mesoscale, regarding their radiative properties linked with their microphysical properties. For these two cases, all the remote sensing measurements are consistent, regarding the thermodynamical phase of clouds.

(2) On October 7, 2001, the combined microphysical models (IHM model in visiblemiddle infrared $)+($ Pristine Hexagonal crystals model in thermal infrared) constitute a good coherent microphysical model which allows to describe cirrus radiative properties in the whole spectrum:

- During one leg of this flight mission, the results obtained from inversion of polar nephelometer measurements indicated an equivalent radius of about $30 \mu \mathrm{m}$ for the ice crystal particles.

- During this leg, the effective radius of cirrus ice crystals, derived from lidar and CLIMAT measurements, led to $20.2 \mu \mathrm{m}<R_{\mathrm{eff}}<30.8 \mu \mathrm{m}$ if we consider hexagonal ice crystals.

- By using single scattering properties of IHM model, the effective radii of ice cloud particles derived from lidar and MINIMIR reflectance meter are slightly smaller than $35 \mu \mathrm{m}$.

(3) Fig. 13c and d shows that the use of the ice aggregate model is also consistent with measurements in thermal infrared. It should be very interesting to investigate the validity of this model in the visible and middle infrared wavelength domains. This could be done by using the solar database constructed by Yang et al. (2000). This will be investigated in the very near future.

(4) During Mission 08, using the complementarity between lidar, CLIMAT, and MINIMIR, we obtained a coherent retrieval of mean ice particle size, in very good agreement with in situ determination. These preliminary analyses of derivation of cirrus microphysical properties are very promising in the perspective of the future space mission AQUA Train.

\section{Acknowledgements}

This work was supported by the DGA (Direction Générales des Armées) under grant number 00-42-149 and the CNES (Centre National d'Etudes Spatiales). The authors are specially grateful to the members of INSU and IGN who operated the Mystère 20 and the members of SOCATA who operated the TBM 700. Thanks are also due to the French weather service at Tarbes-Ossun airport, and to Dr. E. Pachart for running IHM and Adding-Doubling codes. The authors are also especially grateful to Dr. Anthony Baran, from UK Met. Office, for providing the infrared optical properties of ice particles. 
FRENCH/DIRAC data are available from Laboratoire d'Optique Atmosphérique, USTL, France. Please contact Dr. P. François (e-mail: philippe.francois@univ-lille1.fr), for any information about data.

\section{References}

Baran, A.J., 2003. Simulation of infrared scattering from ice aggregates by use of a size-shape distribution of circular ice cylinders. Appl. Opt. 42, 2811-2818.

Baran, A.J., Havemann, S., Mackowski, D., 2001. A database of hexagonal column optical properties for wavelengths rahging between 0.2 microns to 30 microns produced for ANNEX 7, Contract $\mathrm{N}^{\circ} 4 \mathrm{~b} / 3 / 02$ DEFRA, UK.

Brogniez, G., Parol, F., Buriez, J.C., Fouquart, Y., 1992. Bidirectional reflectances of cirrus clouds modelized from observations during the International Cirrus Experiment'89. In: Keevallik, S., Karner, O. (Eds.), Proceedings of the International Radiation Symposium. A. Deepak Publishing, Tallinn, Estonia, pp. 133-136. 3-8 August.

Brogniez, G., Pietras, C., Legrand, M., Dubuisson, P., Haeffelin, M., 2003. A high-accuracy multiwavelength radiometer for in situ measurements in the thermal infrared: Part II. Behavior in field experiments. J. Atmos. Ocean. Technol. 17, 1203-1214.

Chepfer, H., Brogniez, G., Sauvage, L., Flamant, P.H., Trouillet, V., Pelon, J., 1999. Remote sensing of cirrus radiative parameters during EUCREX'94. Case study of 17 April 1994: Part II. Microphysical models. Mon. Weather Rev. 127, 504-518.

C.-Labonnote, L., Brogniez, G., Doutriaux-Boucher, M., Buriez, J.C., Gayet, J.F., Chepfer, H., 2000. Modeling of light scattering in cirrus clouds with inhomogeneous hexagonal monocrystals: comparison with in situ and ADEOS-POLDER measurements. Geophys. Res. Lett. 27, 113-116.

C.-Labonnote, L., Brogniez, G., Buriez, J.C., Doutriaux-Boucher, M., Gayet, J.F., Macke, A., 2001. Polarized light scattering by inhomogeneous hexagonal monocrystals: Validation with ADEOS-POLDER measurements. J. Geophys. Res. 106, 12139-12153.

Crépel, O., Gayet, J.F., Fournol, J.F., Oshchepkov, S., 1997. A new airborne Polar Nephelometer for the measurements of optical and microphysical cloud properties. Ann. Geophys. 15, 451-459.

De Haan, J.F., Bosma, P.B., Hovenier, J.W., 1986. The adding method for multiple scattering calculations of polarized light. Astron. Astrophys. 183, 371-391.

Deschamps, P.Y., Bréon, F.M., Leroy, M., Podaire, A., Bricaud, A., Buriez, J.C., Sèze, G., 1994. The POLDER mission: Instrument characteristics and scientific objectives. IEEE Trans. Geosci. Remote Sens. $32,598-615$.

Dubuisson, P., Buriez, J.C., Fouquart, Y., 1996. High spectral resolution solar radiative transfer in absorbing and scattering media: Application to the satellite simulation. J. Quant. Spectros. Radiat. Transfer 55, $103-126$.

Gayet, J.F., Auriol, F., Oshchepkov, S.L., Schröder, F., Duroure, C., Febvre, G., Fournol, J.F., Crépel, O., Personne, P., Daugeron, D., 1997. In situ optical and microphysical measurements with a new airborne "Polar Nephelometer". Geophys. Res. Lett. 25, 971-974.

Giver, L.P., Chackerian Jr., C., Varanasi, P., 2000. Visible and near infrared $\mathrm{H}_{2} \mathrm{O}$ line intensity corrections for HITRAN-96. J. Quant. Spectros. Radiat. Transfer 66, 101-105.

Inoue, T., 1985. On the temperature and effective emissivity determination of semi-transparent cirrus clouds by bispectral measurements in the $10 \mu \mathrm{m}$ window region. J. Meteorol. Soc. Jpn. 63, 88-98.

Jourdan, O., Oshchepkov, S., Shcherbakov, V., Gayet, J.F., Isaka, H., 2003. Assessment of cloud optical parameters in the solar region: retrievals from airborne measurements of scattering phase functions. J. Geophys. Res. 108, No. D18, 4572, doi:10.1029/2003JD003493.

Knapp, W.H., Hess, M., Stammes, P., Koelemeijer, R.B.A., Watts, P.D., 1999. Cirrus optical thickness and crystal size retrieval from ATSR-2 data using phase functions of imperfect hexagonal ice crystals. J. Geophys. Res. 104, $31721-31730$.

Legrand, M., Pietras, C., Brogniez, G., Haeffelin, M., 2000. A high-accuracy multiwavelength radiometer for in situ measurements in the thermal infrared: Part I. Characterization of the instrument. J. Atmos. Ocean. Technol. 17, 1203-1214. 
Liou, K.N., 1986. Review. Influence of cirrus clouds on weather and climate processes: A global perspective. Mon. Weather Rev. 114, 1167-1199.

Mc Clatchey, R.A., Fenn, R.W., Selby, J.E.A., Volz, F.E., Garing, J.S., 1971. Optical properties of the atmosphere (revised). AFCRL-71-0279, Environmental research papers, No 354, 85 pp.

Miloshevich, L.M., Heymsfield, A.J., 1996. A balloon-borne continuous cloud particle replicator for measuring vertical profiles of cloud microphysical properties: Instrument design, performance and collection efficiency analysis. J. Atmos. Ocean. Technol. 14, 753-768.

Oshchepkov, S.L., Isaka, H., Gayet, J.F., Sinyuk, A., Auriol, F., Havemann, S., 2000. Microphysical properties of mixed-phase and ice clouds retrieved from in situ airborne "Polar Nephelometer" measurements. Geophys. Res. Lett. 27, 209-213.

Parol, F., Buriez, J.C., Brogniez, G., Fouquart, Y., 1991. Information content of AVHRR channels 4 and 5 with respect to the effective radius of cirrus cloud particles. J. Appl. Meteorol. 30, 973-984.

Pelon, J., Flamant, P.H., Meissonnier, M., 1990. The French airborne backscatter lidar LEANDRE-1: Concept and operation. 15th International Laser Radar Conference, Tomsk, USSR, June.

Platt, C.M.R., 1979. Remote sounding of high clouds: I. Calculation of visible and infrared optical properties from lidar and radiometer measurements. J. Appl. Meteorol. 18, 1130-1143.

Raschke, E., Schmetz, J., Heintzenberg, J., Kandel, R., Saunders, R.W., 1990. The International Cirrus Experiment (ICE)-A joint European Effort. ESA J. 14, 193-199.

Raschke, E., Flamant, P., Fouquart, Y., Hignett, P., Isaka, H., Jonas, P.R., Sunquist, H., Wendling, P., 1998. Cloud-radiation studies during the European Cloud Radiation Experiment (EUCREX). Surv. Geophys. 19, $89-138$.

Rothman, L.S., Chance, K., Schroeder, J., Goldman, A., 2001. New edition of HITRAN data base. 11th ARL Science Team Meeting Proceedings, Atlanta, Georgia, USA. March 19-23.

Sauvage, L., Chepfer, H., Trouillet, V., Flamant, P.H., Brogniez, G., Pelon, J., Albers, F., 1999. Remote sensing of cirrus radiative parameters during EUCREX'94. Case study of 17 April 1994: Part I. Observations. Mon. Weather Rev. 127, 486-503.

Stamnes, K., Tsay, S.C., Wiscombe, W., Jayaweera, K., 1988. Numerically stable algorithm for discrete-ordinatemethod radiative transfer in multiple scattering and emitting layered media. Appl. Opt. 12, 2502-2509.

Takano, Y., Liou, K.N., 1989. Solar radiative transfer in cirrus clouds: Part I. Single-scattering and optical properties of hexagonal ice crystals. J. Atmos. Sci. 46, 3-19.

Tobin, D.C., Best, F.A., Brown, P.D., Clough, S.A., Dedecker, R.G., Ellingson, R.G., Garcia, R.K., Howell, H.B., Knuteson, R.O., Mlawer, E.J., Revercomb, H.E., Short, J.F., van Delst, P.F., Walden, V.P., 1999. Downwelling spectral radiance observations at the SHEBA ice station: water vapor continuum measurements from 17-26 micrometer. J. Geophys. Res. 104, 2081-2092.

Warren, S.G., 1984. Optical constants of ice from the ultraviolet to the microwave. Appl. Opt. 23, 1206-1225.

Warren, S.G., Hahn, J., London, J., Chervin, R.M., Jenne, R.L., 1988. Global distribution of total cloud cover and cloud type amounts over the ocean, NCAR Tech. Note, TN-317+ STR, Boulder, CO.

WCP, 1986. A preliminary cloudless standard atmosphere for radiation computation. WCP-112, Available through WMO in Geneva.

Wu, M.C., 1987. A method for remote sensing the emissivity, fractional cloud cover, and cloud top temperature of high-level thin clouds. J. Clim. Appl. Meteorol. 26, 225-233.

Yang, P., Liou, K.N., 1996. Geometric-optics-integral-equation method for light scattering by non spherical ice crystals. Appl. Opt. 35, 6568-6584.

Yang, P., Liou, K.N., Wyser, K., Mitchell, D., 2000. Parameterization of the scattering and absorption properties of individual ice crystals. J. Geophys. Res. 105, 4699-4718.

Young, A.T., 1980. Revised depolarisation corrections for atmospheric extinction. Appl. Opt. 19, 3427-3428.

Young, S., 1995. Analysis of lidar backscatter profiles in optically thin clouds. Appl. Opt. 34, 7019-7031. 